\title{
Capacity Analysis for Approach Channels Shared by LNG Carriers
}

\author{
Xiang Gao ${ }^{1,2}$, Linying Chen ${ }^{1,2, *}$, Pengfei Chen ${ }^{1,2}$, Yu Luo ${ }^{1}$ and Junmin Mou ${ }^{1,2}$ \\ 1 School of Navigation, Wuhan University of Technology, Wuhan 430063, China; \\ xiang.gao@whut.edu.cn (X.G.); pfchenly@outlook.com (P.C.); WutLy@whut.edu.cn (Y.L.); \\ moujm@whut.edu.cn (J.M.) \\ 2 Hubei Key Laboratory of Inland Shipping Technology, Wuhan University of Technology, \\ Wuhan 430063, China \\ * Correspondence: linyingchen@whut.edu.cn
}

Received: 28 July 2020; Accepted: 7 September 2020; Published: 9 September 2020

\begin{abstract}
The transport of liquefied natural gas (LNG) has significant impact on traffic capacity of waterways, especially the approach channels shared by LNG carriers and other types of ships (general cargo ships, container ships, etc.). Few studies take the behavioral characteristics of LNG carriers and their impacts into consideration. In this paper, we propose a framework for capacity analysis of shared approach channels based on the spatial-temporal consumption method. It consists of three modules: (1) the tide module predicts the tidal height and tidal time for identifying the time windows for LNG carriers; (2) the spatial-temporal consumption module is introduced to calculate the capacity of approach channels; (3) the LNG carrier navigation module is for analyzing the characteristics of LNG carriers and the impact on the capacity of approach channels. A spatial-temporal indexed chart is designed to visualize the utilization of the spatial-temporal resources. A case study on the approach channel of Yueqing Bay near the east coast of China is conducted to verify the effectiveness of the framework. The utilization rates of the approach channel and the impact of LNG carriers are presented using our method. The results of the case study indicate that the proposed traffic capacity analyzing framework can provide support for making traffic management strategies.
\end{abstract}

Keywords: capacity analysis; shared approach channel; LNG carriers; spatial-temporal consumption method

\section{Introduction}

\subsection{Background}

World globalization and containerization have led to a significant increase in ship traffic in most of the commercial ports around the world. Therefore, ports face a growing demand for shipping and cargo handling. Traffic capacity is a crucial indicator for identifying waiting times or delays, which indicate the performance of a port. As the approach channels are usually the bottlenecks of the ports [1], capacity analysis of the approach channels is essential when designing a port, or making traffic management strategies, especially for those ships carrying dangerous goods, such as liquefied natural gas (LNG).

Sustainable development has received increased attention in recent decades. LNG is regarded as the most promising alternative to traditional fossil energy. The global demand for LNG will reach up to 4.5 trillion cubic meters by 2030 [2]. As a primary means of transport, the dimensions of the mainstream LNG carrier is more than 30 times the earliest LNG carrier (Methane Pioneer), which was built in America in 1959, with more than 100,000 Gross Tonnage (G.T.). Only a few ports provide the special approach channels for LNG carriers in China, such as "Caofeidian" and "Dalian" port. 
Most of the ports do not have adequate budget and superior natural conditions to construct specific channels for LNG carriers, such as in the Damaiyu ports and Putian ports. LNG carriers have to navigate in the shared channels with other types of ships (OTS), such as cargo ships and container ships [3]. For the sake of safety, LNG carriers have many specific requirements. For example, LNG carriers demand a larger mobile safety zone than OTS because the dimensions of LNG carriers are usually huge. They have to make use of the tide to pass through the channels. When an LNG carrier is sailing in a two-way channel, only the ships that have the same direction with the LNG carrier can enter the channel. Ships from other directions should wait.

In this paper, we propose a framework for capacity analysis of approach channels shared by LNG carriers and OTS, including the tide module, the spatial-temporal consumption module, and the LNG carrier navigation module. The characteristics of the LNG carriers are analyzed as well as their impact on the capacity of channels. A case study of approach channels in Yueqing Bay near the east coast of China is used to demonstrate the effectiveness of the proposed framework.

\subsection{Literature Review}

In this paper, the capacity of an approach channel is defined as the number of the ships passing through the channel section per unit time. To the best of our knowledge, few pieces of literature on capacity analysis consider the impact of LNG carriers. In this part, related research on capacity analysis and LNG shipping is reviewed.

(1) Traffic Capacity Analysis.

Since capacity is a significant indicator of traffic management, many works have been done in past decades. Two types of methods are applied to estimate or quantitatively analyze the traffic capacity.

One is the theoretical calculation. Bellsolà Olba et al. (2019) [4] presented the conflict technique to estimate the traffic capacity of the interaction of the waterways, which was based on the analogy of roads and channels. Zhu et al. (2009) [5] used the optimization principle and nonlinear ship-following theory to build the relationship between the safe distance and ship speed; he constructed the calculation model to study the capacity from a microscopic angel. Zhang et al. (2016) [6] studied the traffic capacity of the bifurcated estuary by using the enormous AIS (Automatic Identification System) data and ship domain theory. The spatial-temporal consumption analysis was applied to calculate the marine traffic capacity of the waterway network; this kind of theory is derived from road traffic. Chen. (2013) [7] took the inland waterway network as the research objects, the spatial-temporal consumption method was used to construct the traffic capacity model, which considered the occupation of different waterway nodes.

The other type of methods is computer simulation. De Oliveira Mota et al. (2020) [8] built the simulation model to estimate the capacity of the Santos port and its approach channel, which considering the whole process of entry and departure. Shang et al. (2020) [9] constructed the Simio-based simulation model to study the impact of the special ships on the approach channel of Meizhou Bay. Hou et al. (2013) [10] built the multi-factor and multi-class index evaluation system to quantitatively estimate the traffic capacity of a waterway, which combined the Analytic Hierarchy Process (AHP) and fuzzy comprehensive evaluation method. Wang et al. (2015) [11] constructed an arena-based seaport operating system simulation model based on the ship-following theory; this model was used to study the traffic capacity of seaports at different safety levels. Later, Wang (2017) [1] built the complicated simulation model for the navigation in the port waters, which takes into the navigation rules, the scale of the anchorage, etc., to assess the relationships between the influencing factors and traffic capacity.

\section{(2) LNG Carriers.}

With the development of the LNG market and the increasing number of LNG carriers, increasing attention has been drawn to this field. Many theoretical studies and experiments have been conducted to assess the risk of LNG carriers. The World Association for Waterborne Transport Infrastructure (PIANC) provides comprehensive guidelines for small to mid-scale LNG terminals and introduced 
safety management, navigation aspects, risk assessments, and so on [12]. Meanwhile, PIANC also proposes some rules for LNG carriers when berthing: there must be sufficient distances from the passing ships, LNG carriers at berth should always pay attention to the cargo type of surrounding berths, the influences of wave or wind, and the performance of support facilities [13]. Vanem et al. (2010) [14] proposed a quantitative evaluation for different generic accident categories and drew an analogy between LNG carriers and OTS. Abdussamie et al. (2018) [15] proposed the fuzzy set method to study the hazardous categories that may happen when LNG carriers were navigating in the open water. Zhang et al. (2011) [16] analyzed the marine accidents involving LNG carriers around the world and evaluated the potential dangers, probability, and consequences of these accidents. Nwaoha et al. (2013) [17] set up the framework to analyze the risks of LNG carriers' operation and primary cause by combining the risk matrix and fuzzy evidential reasoning (FER). Liu et al. (2019) [3] constructed the simulation model to analyze the correlations between the influencing factors and efficiency or safety in restricted two-way waterways; these factors were mainly caused by the navigation of LNG carriers and special navigation rules. Federica et al. (2018) [18] used the risk matrix approach that considering the surrounding territory and industrial facilities, to assess the risk level when LNG carriers approaching bunkering terminals trough approach channels. Frederic (2018) [19] analyzed the risks of Yamal LNG project from multiple angels, such as the construction of LNG terminal, the risk of navigation, the differences of dredging works comparing with the conventional ports, the experiences of the Yamal LNG project was regarded the reference for the future LNG project in Arctic area.

According to the safety management system of "human-machine-environment-control", Jiao et al. (2011) [20] analyzed the hidden risk linked to the safety of LNG carriers from many aspects. Maimun et al. (2012) [21] proposed a model to analyze the maneuverability difficulty, which was caused by the interaction forces between the LNG carrier and the adjacent bank in a narrow channel. Tarek (2009) [22] developed a multiple attribute risk assessment methods of LNG carrier based on the use of fuzzy rules, rule base, and fuzzy inference engine. Chen et al. (2018) [23] presented an experimental design methodology of full mission simulation for LNG carriers maneuvering in port water, and this method is demonstrated in detail in the experiment of Meizhou Bay. Wen et al. (2013) [24] proposed a method for defining the width of the LNG mobile safety zone based on ship-collision probability and quantitative risk analysis.

To conclude, most existing studies aimed at the operational and navigational risks of LNG transportation. With the increase of the number and scale of LNG carriers, the impact of LNG carriers on the traffic capacity needs further investigation.

\subsection{Contributions}

This paper focuses on the navigation process, i.e., the process that a ship enters the approach channel until it docks at the terminals. We propose a framework for capacity analysis of approach channels shared by LNG carriers and OTS. The framework consists of three modules, i.e., the tide module, the spatial-temporal consumption module, and the LNG carrier navigation module. The main contributions of this paper are as follows:

Firstly, we propose a comprehensive framework for capacity analysis of shared approaching channels considering the characteristics of the navigation of LNG carriers.

Secondly, a tide module that is widely used by the officers on board is integrated into the proposed framework, making the framework closer to the navigation practice.

Thirdly, we design a spatial-temporal indexed chart to visualize the resource consumption and the remaining capacity of an approach channel, which supports the authorities to make traffic management strategies.

Briefly, this paper uses the spatial-temporal consumption method to propose a framework to analyze the influences of the LNG carriers on traffic capacity, and results are regarded as the reliable reference for the authority to make reasonable entry plans. 


\subsection{Organization}

The remainder of this paper is structured as follows: The capacity analysis framework is presented in Section 2. Details about the modules are given in Section 3. In Section 4, a case study is carried out to illustrate the effectiveness of the proposed framework. Section 5 provides conclusions and further research directions.

\section{Methodology}

Many potential and invisible factors affect the channel traffic. These factors have random effects and vary among different ports, such as wave, tide, number and operation time of berths, weather conditions, and the scale of anchorages. This paper focuses on the procedure of navigation, especially the attributes related to channels and ships, other than the operation at the terminals or berths.

Figure 1 provides the proposed capacity analysis framework for approach channels, including the generic spatial-temporal consumption module, and the LNG carrier navigation module, and the tide module.

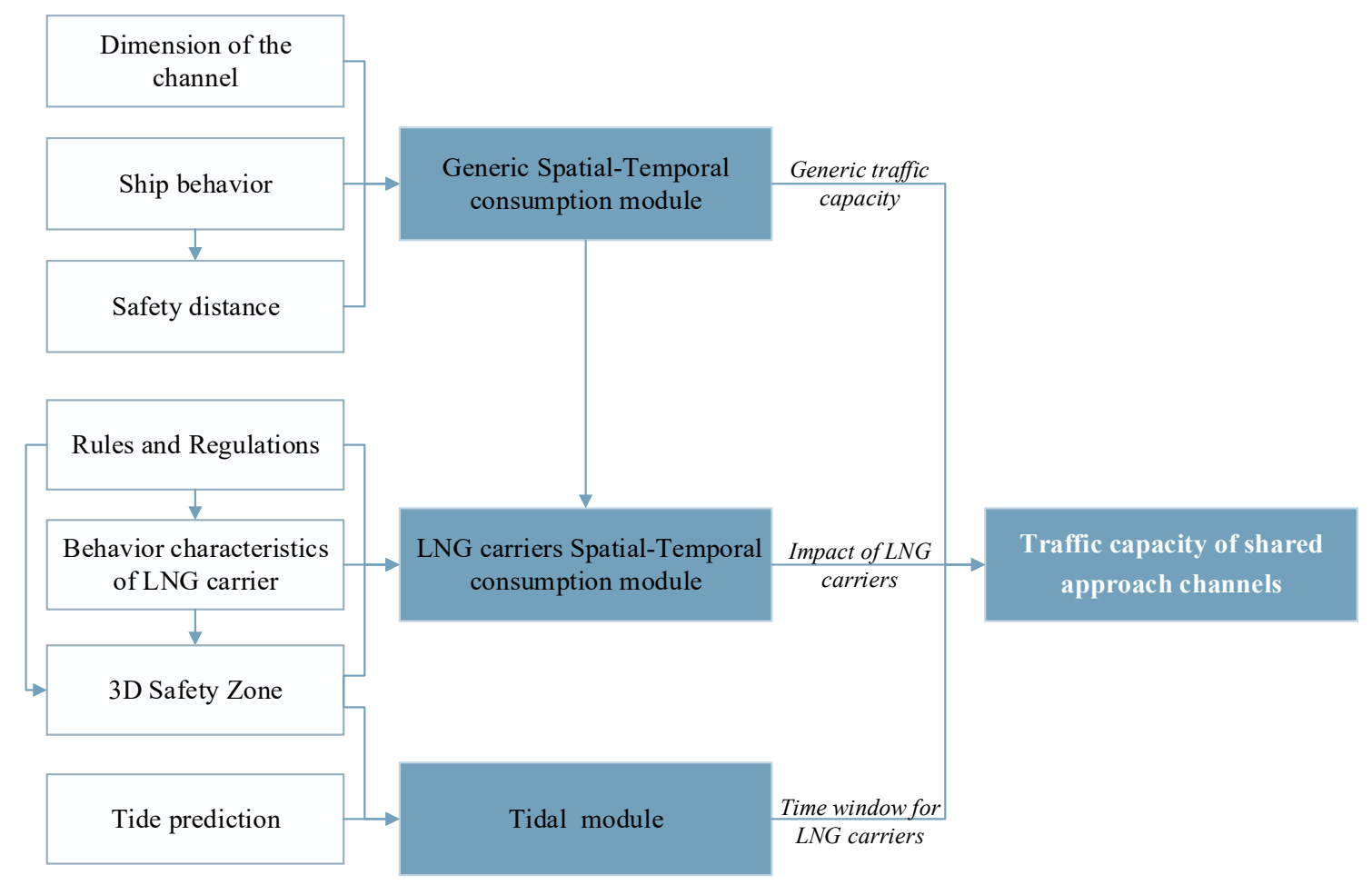

Figure 1. The framework of capacity analysis for shared approach channels. LNG, liquefied natural gas; 3D, three-dimensional.

(1) The Generic Spatial-Temporal Consumption Module.

The generic spatial-temporal consumption module calculates the overall spatial-temporal resources and the generic traffic capacity of the channels when there are only OTS.

(2) The LNG Carrier Navigation Module.

LNG carriers have many special requirements because of the dangers of the loaded LNG. When LNG carriers are navigating in the approach channel, it is compulsory that the OTS wait in the berths or anchorage, except those ships satisfy certain conditions: the OTS whose courses are corresponding with the LNG carriers; the OTS in front of LNG carriers and their velocity is higher than the LNG carriers; or the OTS that follow the LNG carriers. In the framework, the LNG carrier 
navigation module describes the whole process of passing through the approach channels and the impact on other ships.

(3) The Tidal Module.

Accurate tidal height prediction is a significant element for safe navigation in approach channels. The variation of the near-shore sea level is mainly caused by the flood tide and ebb tide [25]. In this module, the historical tidal data and the classical method are combined to predict the precise tidal height at an arbitrary time. Combining with the under keel clearance described in the three-dimensional (3D) mobile safety zone, the time windows for LNG carriers sailing in the approach channels are determined.

\section{Capacity Analysis for Shared Approach Channels}

\subsection{Assumptions}

To ensure the generality of the method and to simplify the model, the following assumptions are made:

1. The OTS navigating in the channel are treated as having the same dimension and the same maneuverability.

2. The anchorage and berths are always available. Ships can find some areas to wait ahead of LNG carriers entering or departing the port.

3. Meteorological conditions are appropriate for navigation.

4. Navigation facilities on the channel are in good condition and provide sufficient supports.

\subsection{Generic Spatial-Temporal Consumption Module}

\subsubsection{Spatial-Temporal Consumption Model}

Based on the spatial-temporal consumption theory and the above assumptions, the available length of the channel and the workable time are regarded as the attributes of the overall resources [26,27].

The total channel spatial-temporal resources can be expressed in Equation (1):

$$
C_{t}=\int_{t_{1}}^{t_{2}} L_{C} \times B_{c} \times N \times d_{t}
$$

where $C_{t}$ is the total spatial-temporal resources; $t_{2}$ and $t_{1}$ represent the period; $L_{C}$ is the overall length of the channel; $B_{c}$ is the maximum available width of the channel; and the $N$ is the number of the passageway in the channel. The list of variables is provided in Appendix A.

Thus, the occupied resources of the individual ship are the Equation (2):

$$
C_{\text {ind }}=\int_{t_{3}}^{t_{4}} h_{\text {ship }} \times b \times d_{t}
$$

where $C_{\text {ind }}$ is the resource that the individual ship occupied; $t_{3}$ and $t_{4}$ are the period that the single ship navigates in the channel; $h_{\text {ship }}$ is the safety distance between the consecutive ships; and $b$ is the track zone width of the individual ship. The illustration of the safety distance between consecutive ships is shown in Figure 2. 


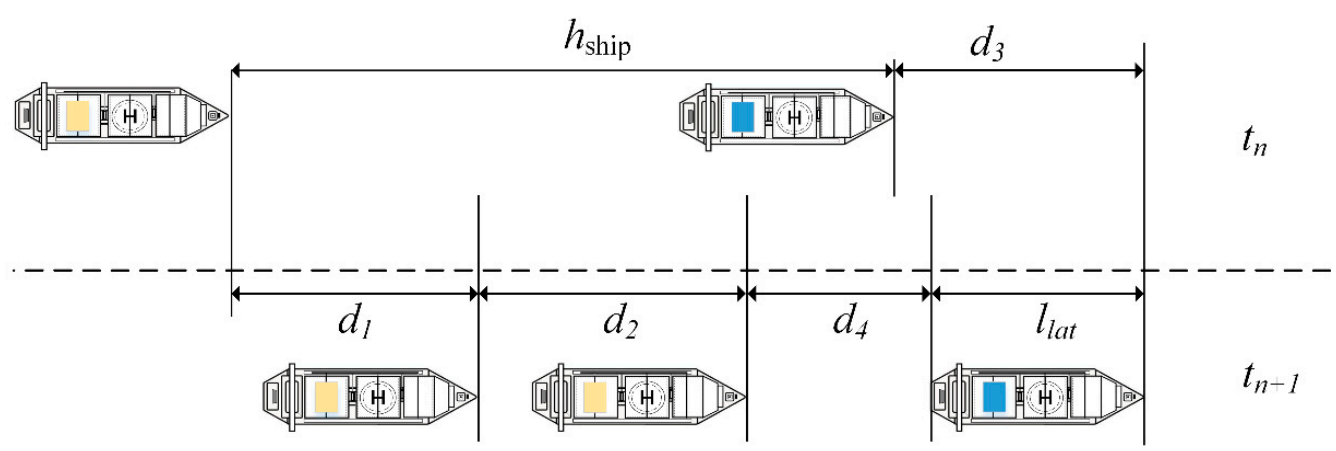

Figure 2. Illustration of the safety distance. $d_{1}$ : Distance of reacting time; $d_{2}$ : crash-stop distance of the later ship; $d_{3}$ : crash-stop distance of the former ship; $d_{4}$ : static safety; $h_{\text {ship }}$ : safety distance; $l_{\text {lat }}$ : length of former ship.

The safety distance between the consecutive ships refers to the distance measured from the bow of the later ship to the bow of the former ship. $h_{\text {ship }}$ plays a vital role in determining the individual occupied spatial-temporal resource. Moreover, it gives the later ship enough time and distance to respond to the emergencies that happen on the former ship. $h_{\text {ship }}$ consisted of five different variables, viz. the distance in reacting time $d_{1}$, the crash-stop distance of the later ship $d_{2}$, the static safety distance $d_{4}$ (the distance that should be kept between two stopped ships), the crash-stop distance of the former ship $d_{3}$, and the length of the former ship $l_{\text {lat }} . h_{\text {ship }}$ is described in Equation (3):

$$
h_{\text {ship }}=d_{1}+d_{2}+d_{4}+l_{\text {lat }}-d_{3}
$$

As assumed, ships in this module are deemed to the same. Therefore, $d_{3}$ and $d_{2}$ have the same values [28]. $d_{1}$ can be expressed as

$$
d_{1}=v_{\text {lat }} \times t_{\text {rea }}
$$

where $t_{\text {rea }}$ is the reaction time. According to the so-called good seamanship, $t_{\text {rea }}$ is about $10 \mathrm{~s}$ with high visibility. $v_{\text {lat }}$ is the velocity of the consecutive ships. According to the achievements of researches conducted by [29], $d_{4}=l_{\text {lat }}$.

Therefore, the traffic capacity of the channel can be calculated with Equation (5):

$$
C=\frac{C_{t}}{C_{\text {ind }}}=\frac{L_{c} \times B_{c} \times T \times N}{h_{\text {ship }} \times b \times t_{\text {ship }}}
$$

where $T$ is the workable time of the channel in a single day, and $t_{\text {ship }}$ is the average time that the individual ship used within $T$. If there is a single traffic flow in the channel, then $B_{c}=b$, Equation (5) is transformed into Equation (6):

$$
C=\frac{C_{t}}{C_{\text {ind }}}=\frac{L_{c} \times T \times N}{h_{\text {ship }} \times t_{\text {ship }}}
$$

\subsubsection{The Impact of Ship Behaviors}

The influence on the traffic flow caused by clearing the channel and restoring the channel order should not be ignored. The sudden increase or the rapid decrease of ships in the channel both result in the appearance of heterogeneous traffic flow. Therefore, the traffic congestion may easily take place, which may increase the risk of collision, and decrease the efficiency. Thus, the timeline of the LNG carriers' impact will extend: it covers the whole procedure from OTS departing the channel until the end of restoring the traffic flow.

The ship behaviors in this paper mean the entering or leaving the channel under the influence of the LNG carriers approaching, see Figure 3. The outbound of the traffic flow means the release of the spatial-temporal resources, a great number of ships bear off the channel. Meanwhile, the beginning of 
OTS outbound is the time point when LNG carriers influence the traffic capacity. Ships satisfy the requirements to navigate together with LNG carriers are only a few. Most of the OTS have to wait. Furthermore, if the port authority adopts the exclusive traffic pattern for LNG carriers, all the OTS are forbidden to navigate in the channel. Although almost entire spatial-temporal resources are released before LNG carriers approaching, the spare spatial-temporal resources are not available to OTS for some time. It can be regarded as the suspension of the traffic flow.

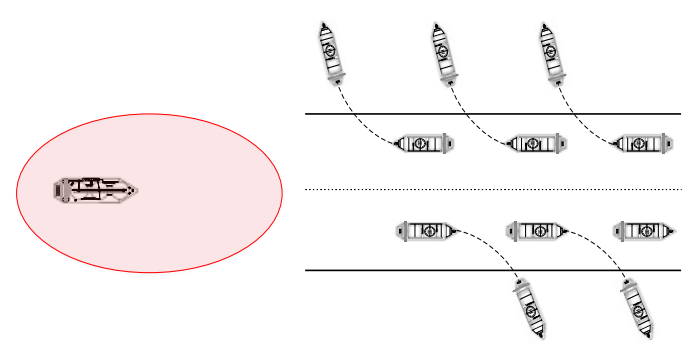

(a)

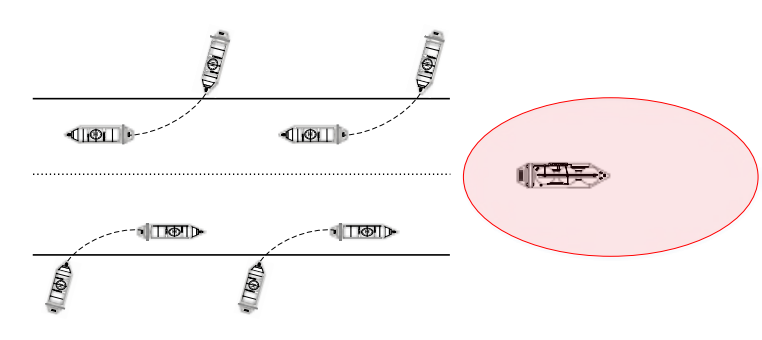

(b)

Figure 3. Behaviors of the ships; (a) outbound, (b) inbound.

\subsection{The LNG Carrier Navigation Module}

\subsubsection{Characteristics of Behaviors of LNG Carriers}

For the sake of safety, many countries have drawn laws and regulations for the specific requirements of LNG carriers, e.g., Code for Design of Liquefied Natural Gas Port and Jetty, LNG Operations in Port Areas, etc. The regulations make recommendations and mandatory orders about berthing, navigating in the channel, departing, and so on. Moreover, lots of significant parameters have made numerical restrictions while entering or leaving ports, e.g., wind velocity, wave height, visibility, flow velocity, traffic control, ship mobile safety zone, etc.

In general, rules and special requirements related to LNG carriers can be summarized as follows:

(1) When the LNG carrier navigates in shared approach channels, OTS, whose courses are opposite to the LNG carrier, are forbidden to enter the channel. OTS should leave the channel before the LNG carrier inbound.

(2) Some ships are allowed to navigate in the long-distance approach channel. The premise is that the LNG carriers have the priority of the navigation, and OTS should leave enough space and time for the LNG carrier.

(3) OTS and LNG carriers can navigate in the same channel under the traffic control, but the LNG carrier should be equipped with escort ships and tugs.

(4) Authorities should set the proper mobile safety zone for LNG carriers when approaching the channel.

(5) The LNG carrier should enter the port in the daytime.

\subsubsection{The 3D Mobile Safety Zones for LNG Carriers}

The first choice to control the risks at the lowest level is establishing the mobile safety zone, which is based on the considerations of the structure of the LNG carriers and the flammability of the loaded cargo. Although the mobile safety zone of an LNG carrier occupies massive spatial-temporal resources of the channel, it is the optimal choice to guarantee the safety operation of LNG carriers.

In this paper, we design a 3D mobile safety zone for an LNG carrier, which can be regarded as the combination of safety distance and under keel clearance (UKC), see Figure 4. 


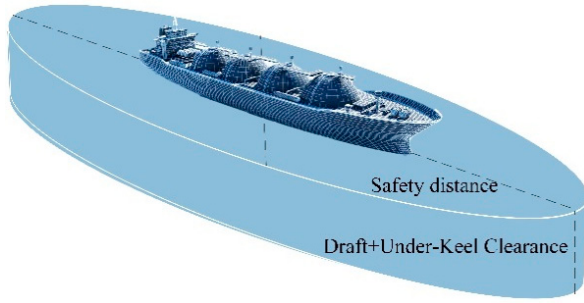

(a)

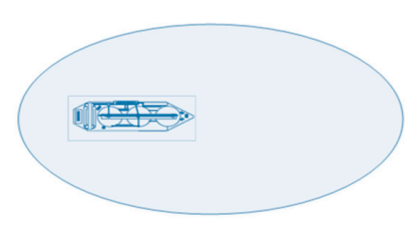

(b)

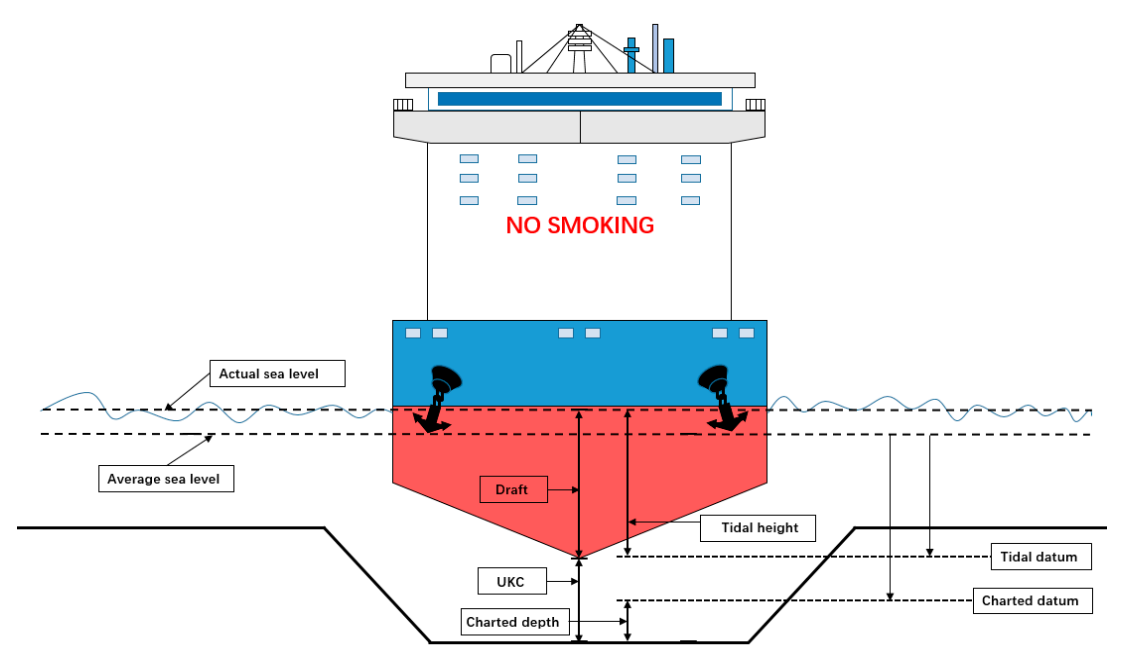

(c)

Figure 4. A 3D mobile safety zone for an LNG carrier. (a) A 3D mobile safety zone for an LNG carrier; (b) top view of the 3D mobile safety zone; (c) front view of the 3D mobile safety zone.

\section{(1) Safety Distance.}

Many aspects determine the scale of the mobile safety zone, such as the velocity of LNG carrier, the maneuverability of the LNG carrier, and the hydrodynamic effects between the hull and bank or other ships [29]. Different ports have different standards for setting the dimensions of the mobile safety zones, see Table 1 . The longitudinal distances from bow and stern of the LNG carriers are usually set as 0.5-2 [NM](NM for Nautical Mile); the transverse distances are set as 0.25-2 [NM]. As the "exclusive" characteristics of LNG carrier navigation, the transverse distances are also often set as the width of the channel.

Table 1. Recommended safety distances of LNG carriers in different countries.

\begin{tabular}{|c|c|c|c|c|c|}
\hline \multirow{2}{*}{ No. } & & \multirow{2}{*}{ Location } & \multicolumn{3}{|c|}{ Dimension of the Mobile Safety Zone } \\
\hline & & & Bow & Stern & Transverse \\
\hline 1 & \multirow{5}{*}{ China } & Dapeng Bay, Shenzhen & $2[\mathrm{NM}]$ & $2[\mathrm{NM}]$ & $2[\mathrm{NM}]$ \\
\hline 2 & & Meizhou Bay, Fujian & $1.5[\mathrm{NM}]$ & $0.5[\mathrm{NM}]$ & $750[\mathrm{M}]$ \\
\hline 3 & & Dalian Port, Liaoning & $1[\mathrm{NM}]$ & $1[\mathrm{NM}]$ & $750[\mathrm{M}]$ \\
\hline 4 & & Guangzhou Port & $4 \times \mathrm{LOA}^{*}$ & $2 \times \mathrm{LOA}$ & Channel width \\
\hline 5 & & Zhoushan Port, Ningbo & $1[\mathrm{NM}]$ & $1[\mathrm{NM}]$ & $500[\mathrm{M}]$ \\
\hline 6 & France & Montoir-de-Bretagne & $2[\mathrm{NM}]$ & $2[\mathrm{NM}]$ & No passage \\
\hline 7 & Canada & & $1[\mathrm{NM}]$ & 1 [NM] & $250[\mathrm{M}]$ \\
\hline 8 & \multirow{4}{*}{ America } & Boston, Massachusetts & $2[\mathrm{NM}]$ & $1[\mathrm{NM}]$ & $500[\mathrm{M}]$ \\
\hline 9 & & Savannah River, Georgia & $2[\mathrm{NM}]$ & $2[\mathrm{NM}]$ & $2[\mathrm{NM}]$ \\
\hline 10 & & San Juan Harbor, San Juan, PR & $0.5[\mathrm{NM}]$ & $0.5[\mathrm{NM}]$ & 0.5 [NM] \\
\hline 11 & & Chesapeake Bay, Maryland & $500[\mathrm{M}]$ & $500[\mathrm{M}]$ & $500[\mathrm{M}]$ \\
\hline
\end{tabular}

* LOA: length overall, the maximum length of a vessel's hull measured parallel to the waterline. NM for Nautical Mile; M for Meter. Data source: [30,31]. 


\section{(2) Under Keel Clearance.}

The UKC is a solvable variable by calculating some accessible ship data. The calculation of UKC should consider the following factors, the ship squat (s), water level measuring error $(\varepsilon)$, and the ship swaying increment $(\omega)$. The squat is the most influential factor among them.

The depth of the open sea is much deeper than the areas near the edge of the continent. According to the experiment results of the effect of water depth on hull resistance, the relative depth $\left(h_{\mathrm{R}}\right)$ is used to distinguish the shallow water and deep water. The relative depth as follows:

$$
h_{\mathrm{R}}=\frac{h_{\text {real }}}{D}
$$

where the $h_{\text {real }}$ is the depth from the ocean floor to the sea level and $D$ is the draft. When $h_{R}$ is less than 4 , this area is regarded as the shallow water. Otherwise, it is supposed to be deep water. When ships are navigating from the open sea approach to the port of destination, the phenomenon of ship sinkage will occur, since most of the channels cannot reach the standard of deep water. Ship sinkage has detrimental impacts in many aspects, e.g., the decrease of ship speed, the increase of trim, the reduction on the rudder performance, etc. Hence, the accurate calculation of the squat becomes necessary.

As for the ship squat, there are simplified empirical formulas and classical theoretical formulas. The later one is divided into two formulas called Tuck formula $\left(s_{1}\right)$ and Hooft formula $\left(s_{2}\right)$. The final result $s$ is the sum of these two variables. The former one is used to compute the mean ship squat, and the following formula is often used to get the bow squat, which is caused by trim change. The Tuck formula [32] is written in Equation (8) and the Hooft formula [33] is presented in Equation (9):

$$
\begin{aligned}
& s_{1}=1.5 C_{b} \cdot L p p \cdot F r^{2} /\left(\frac{d_{\text {channel }}}{D} \cdot \frac{L p p}{B}\right) \\
& s_{2}=\frac{F n^{2}}{\sqrt{1-F n^{2}}} \cdot \frac{V}{(0.1 L p p)^{3}} \cdot 0.001 L p p
\end{aligned}
$$

where $L p p$ is the length between perpendiculars; $C_{b}$ is the block coefficients of the ship; $d_{\text {channel }}$ represent the depth of the channel; $B$ is the molded breadth; $V$ is ship displacement; $F r$ is the Froude number of ship length, and $F n$ is the Froude number of channel depth.

According to the formulas mentioned above, the squat is heavily involved with $v_{l}$ and $C_{b}$. The accurate squat can be measured through the accessible data and provided formula. Need to add that, the calculation is corresponding with the facts for the new ship. However, the result is relatively accurate when the ship has been kept in service for many years.

Once the squat is obtained, change $\varepsilon$ into the centesimal grade. $\varepsilon$ and $\omega$ cannot be made quantitative analysis, since there are so many influenced factors, e.g., the atmospheric pressure, wave force, swell force, wind force and the error of instrument, etc. Although these two parameters are difficult to estimate, the relatively reasonable and logical number can be accessed by experts' experience and enormous statistic data. Last, the UKC is given in Equation (10):

$$
U K C=s \cdot \varepsilon+\omega
$$

\subsubsection{Spatial-Temporal Consumptions of LNG Carriers}

When computing the consumed spatial-temporal resources of the LNG carriers, the mobile safety zone of the LNG carriers is being calculated. Setting up the mobile safety zone is an efficient way to ensure the safety of human life and property.

The procedure of LNG carriers entering or leaving the port can be divided into three steps:

(1) Clear the channel. OTS are compelled to leave the channel and wait in the anchorage or the berth before the front edge of the mobile safety zone approaching the entrance of the channel. 
(2) LNG carriers pass through the channel. The LNG carriers proceed into the channel at the safe speed with enough tugs, patrol boats, or even the empirical pilots on board. OTS that meet the related requirements can follow the LNG carrier.

(3) Restore the channel order. When the back edge of the LNG carriers' mobile safety zone leaving the channel sideline, the blocked ships can enter the proper channel. The traffic flow will continue like ever.

The spatial-temporal resources of LNG carriers are mainly determined by the area of the mobile safety zone and navigation time. The scale of the mobile safety zone in different ports sees Table 1.

There are no specific rules or laws to set up the scale of the mobile safety zone; only some fuzzy and qualitative regulations are written in the legislation. Authority should set the range of the mobile safety zone base on the conditions of the channel and the characteristic of the traffic flow.

The length in the longitudinal direction is $L_{z o n e}$, and the width in the transverse direction is $B_{\text {zone }}$. The navigation plane area used by the mobile safety zone is $A_{\mathrm{LNG}}$, which is given in Equation (11):

$$
A_{\mathrm{LNG}}=L_{\mathrm{zone}} \times B_{\mathrm{zone}}
$$

The navigation time of $\mathrm{LNG}$ carriers is $T_{\mathrm{LNG}}$, which is obtained by the Equation (12):

$$
T_{\mathrm{LNG}}=\frac{L_{c}}{V_{\mathrm{LNG}}}
$$

where $V_{L N G}$ is the safe velocity of the LNG carrier. Due to the tide riding pattern, the used spatial-temporal resources are written in Equation (13):

$$
C_{\mathrm{LNG}}=A_{\mathrm{LNG}} \times T_{\mathrm{LNG}}
$$

\subsection{The Tide Module}

\subsubsection{Tide Prediction}

A significant number of marine accidents, e.g., grounding, stuck on the rock, ship out of control, etc., are originated from the miscalculation of the tidal height and tidal time. There are two different editions of Tide Tables for calculating the tidal level and tidal time. One is Admiralty Tide Tables, and China Navy Hydrographic Office publishes the other version. The method is various in two editions, the formula solution, and the isosceles trapezoidal picture are adopted by Chinese edition, the simplified harmonic method, which is used to plot the tidal curves is included in the Admiralty Tide Tables. The former is usually used when ships navigate in the vicinity of the Chinese territorial water area.

The tidal data of the destination is needed when predicting the tide, including the tidal time and tidal height of the high (low) tide. There are three ways to access tidal data: (a) tide tables; (b) using the tide-predicting manual; and (c) using the tidal information panel.

According to the data, the tidal time at any height and the tidal height at any time can be obtained. If the officer wants to get the tidal height $\left(h_{N}\right)$, the equation can be written in Equation (14).

$$
h_{N}=h_{\text {high }}-\frac{R}{2}\left[1-\cos \left(\frac{t_{N}-t_{\text {high }}}{t_{\text {low }}-t_{\text {high }}} \times 180^{\circ}\right)\right]
$$

where $h_{\text {high }}$ and $t_{\text {high }}$ is the height and duration of the high tide respectively, $h_{\text {low }}$ and $t_{\text {low }}$ is the height and duration of the low tide. $R$ is the tidal range and can be acquired by Equation (15):

$$
R=h_{\text {high }}-h_{\text {low }}
$$


Similarly, the arbitrary tidal can be accessed by using the $h_{\text {low }}$ :

$$
h_{N}=h_{\text {low }}+\frac{R}{2}\left[1-\cos \left(\frac{t_{N}-t_{\text {low }}}{t_{\text {high }}-t_{\text {low }}} \times 180^{\circ}\right)\right]
$$

\subsubsection{Determination of the Time Windows for LNG Carriers}

The primary conditions for safe navigation are precise height and time of the tide. That is to say, and the tidal level must be determined at first. To ensure the safety of LNG ship navigation, the UKC, the draft $(D)$, the height of the tide $\left(h_{\text {tide }}\right)$, the charted depth $\left(d_{\text {chart }}\right)$, tidal datum $(T D)$, and the chart datum $(C D)$ must be in a logical relevance as follows:

$$
U K C+D \leq h_{\text {tide }}+(C D-T D)+d_{\text {chart }}
$$

where $h_{\text {tide }}$ is an unknown variable; $C D, T D, d_{\text {chart }}$, and $D$ are supposed to be constant because these parameters will not change by a wide margin in a short time. Then, with the prediction of the tide, the 3D mobile safety zones of LNG carriers, the time windows for LNG carriers using the approach channels can be determined.

\subsection{The Integrated Module}

\subsubsection{Steps of Calculation}

Based on the above modules, the traffic capacity of the channel is calculated by the spatial-temporal consumption theory; the steps are followed:

(1) Calculating the Tidal Time and Tidal Level.

The proposed method is used to compute the ship squat and UKC. Then the tidal height is obtained by these parameters, viz. UKC, $C D, T D, D, d_{\text {chart }}$ and $h_{\text {tide }}$. The latest tidal data and practical methods are combined to compute the tidal time, which is satisfied with the safe navigation of the LNG carriers. Once the tidal time is determined, the LNG carriers can get the accurate time window to enter the channel.

(2) The Total Spatial-Temporal Resources of the Channel.

The total spatial-temporal resources $C_{t}$ is the navigable water area for OTS and LNG carriers in a certain time. It also represents the maximum number of ships that the channel contains within an amount of time.

(3) The Influences Caused by the Inbound and Outbound Ship Behaviors.

The clearance of the channel and restoration of the traffic flow also create dramatic effects on the overall traffic capacity. The results of the two disturbances are in different degrees and the clearance of channel causes extra waste to the spatial-temporal resources. However, the outbound of OTS will release the spatial-temporal resources but bring the suspension to the movements of the spatial-temporal resources, which expressed as flows:

$$
C_{\text {sto }}=\int_{T_{0}}^{T_{1}} L_{C} \times B_{c} \times N \times d_{t}
$$

where, $T_{0}$ is the beginning point in time of the clearance of the channel, while $T_{1}$ is the ending point in time, other parameters are the same as Equation (1).

(4) The Occupied Spatial-Temporal Resources of LNG Carriers Navigation. 
The occupied spatial-temporal resources of the LNG carriers $\left(C_{\mathrm{LNG}}\right)$ are determined by the mobile safety zone.

(5) Get the Loss of the Spatial-Temporal Resources.

This paper assumes the time for the port operation time in one day is $24 \mathrm{~h}$, and the total spatial-temporal resources can be divided into two parts, viz. the used spatial-temporal resources by OTS $\left(C_{\text {ord }}\right)$ and the occupied spatial-temporal resources by the LNG carriers $\left(C_{t \ln g}\right)$, these two variables are described in the Equations (19) and (20) respectively:

$$
\begin{gathered}
C_{\text {ord }}=C_{t} \times \frac{24-T_{\mathrm{LNG}}}{24}-C_{\text {sto }}+\frac{3}{16} \times\left(C_{t} \times \frac{T_{\mathrm{LNG}}}{24}\right) \\
C_{t \ln g}=C_{t} \times \frac{T_{\mathrm{LNG}}}{24}
\end{gathered}
$$

Assume that the arrival rate is 1 LNG carrier per day, the unused spatial-temporal resources $\left(C_{\text {uopd }}\right)$ within the time of LNG carrier's navigation is figured out as follows:

$$
C_{\mathrm{uopd}}=\frac{3}{4} \times\left[C_{t} \times \frac{T_{\mathrm{LNG}}}{24}-C_{\mathrm{LNG}}\right]
$$

Then, the loss rate of spatial-temporal resources $\left(P_{l o s}\right)$ can be calculated with Equations (22) and (23):

$$
\begin{gathered}
C_{\mathrm{los}}=C_{\mathrm{sto}}+C_{\mathrm{uopd}}+C_{\mathrm{LNG}} \\
P_{\mathrm{los}}=\frac{C_{\mathrm{los}}}{C_{t}} \times 100 \%
\end{gathered}
$$

\subsubsection{Spatial-Temporal Indexed Chart}

Visualization provides a direct way for the authorities to have insight into the states of the approach channels when making decisions. Thus, we proposed a spatial-temporal indexed chart, which visualizes the occupied or spared situation of the specific spatial-temporal resources in longitude, latitude, and time coordinate system. The total spatial-temporal resources are sliced into hundreds or thousands of spatial-temporal units.

This chart constructs a three-dimension coordinate system. The $X$-axis is the length of the channel, $Y$-axis is the largest navigable width of the channel, and the $Z$-axis is the time of navigation. The approach channel can be divided into many units. Various colors are assigned to each unit or each group of units to indicate the spatial-temporal situation of the channel. Blue represents the traffic flow of OTS; white is the unused state of the channel, yellow is the spatial-temporal resources used by LNG carrier. The different spatial-temporal unit is assigned a confirmed location. The total channel resources are divided as units of nautical mile and hour.

Thus, the spatial-temporal indexed chart can reconstruct the whole process of the LNG carrier when navigates in the channel. Meanwhile, this chart shows the essence of the spatial-temporal method. The spatial-temporal indexed chart tells three kinds of information.

(1) Show the Process of Ships Navigation.

The whole process of the ships entering the port is presented by the change of the spatial-temporal units, see Figure 5. If ships navigate without the impact of LNG carriers, the change of the spatial-temporal units is presented in a two-way approach channel as follows. Each number represents a ship, except the LNG carrier; the different units marked with the same name describe the process of the same ship passing through this part of the approach channel.

If the spatial-temporal units with "Zero" are selected as the objective ship, the spatial-temporal units marked with a positive number enter this channel later than the objective ship. For the same 
reason, units marked with a negative number enter there earlier than the objective ship. All of the units marked with zero represent the whole process passing through this channel.

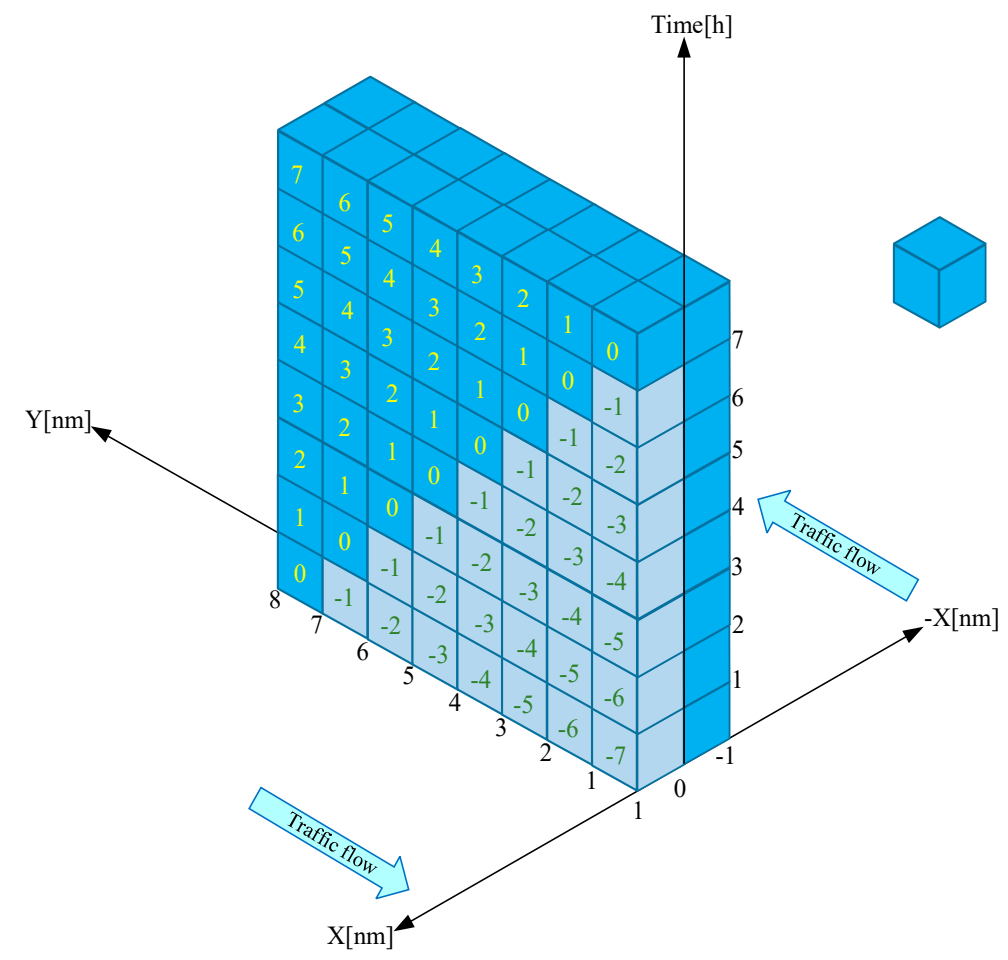

Figure 5. Process of ships passing through the channel.

(2) The Total Used Spatial-Temporal Resources by the Individual Ship.

The total used spatial-temporal units by individual ships are observed by this chart directly. the total units are calculated by summing the spatial-temporal units at different times, and different locations at a certain time, as shown in Figure 6.
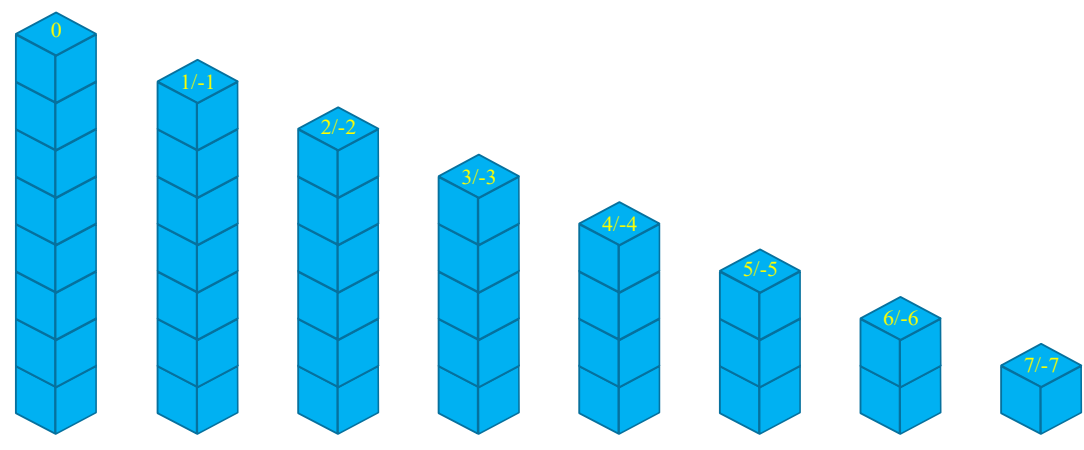

Figure 6. The used spatial-temporal units of each ship.

(3) The Maximum Number of Ships.

The top level of the spatial-temporal indexed chart tells the maximum number of ships that a particular part of the channel contains. The top level of the spatial-temporal indexed chart gives the maximum amount that the channel contains at the end of the navigation of the "Zero" ship. Perhaps the bottom level of this chart can also give the maximum number of the ship, but in complex traffic flow, such as the traffic flow under the influence of LNG carriers, the bottom level cannot give the corresponding number. 


\section{Case Study}

\subsection{Setup}

To illustrate the effectiveness of the proposed method and to analyze the impact of velocity, mobile safe zone, etc., we selected the Yueqing Bay on the east coast, China, as the objective water area; see Figure 7. The Yueqing Bay's main channel is a typical approach channel shared by OTS and LNG carriers.

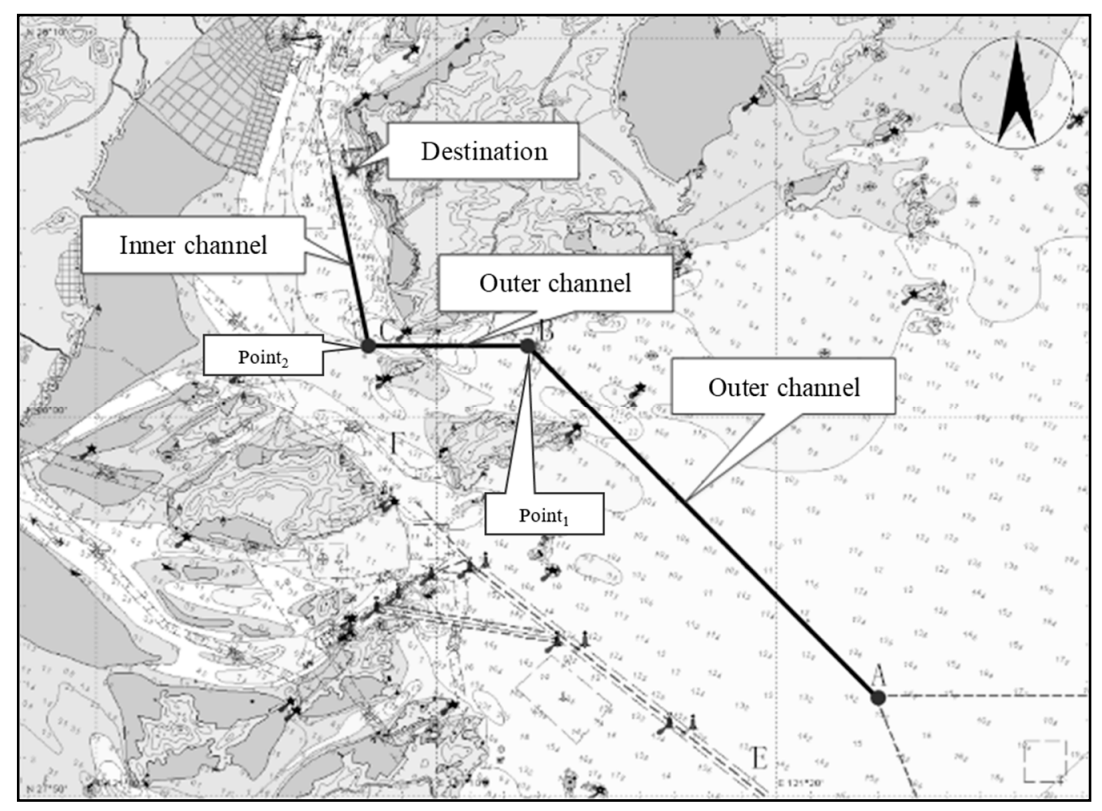

Figure 7. Channel chart for Yueqing Bay.

\section{(1) Approach Channel.}

Yueqing Bay's main channel is a crucial approach channel connected to the open sea and the coastal water, and it is the only channel for LNG carriers entering or leaving the Damaiyu LNG terminal. The approach channel is a two-way channel. LNG carriers arrive at the destination without navigating the whole channel, and the inner channel is $6000[\mathrm{M}]$, Detailed parameters of Yueqing Bay's main channel are provide in Table 2.

Both outer channel and inner channels have several shallow points, and the risk of grounding increases because of these points. However, this area has sufficient tidal resources and large tidal range, so that the LNG carriers can navigate by the tide.

Table 2. Parameters of Yueqing Bay's main channel.

\begin{tabular}{lccccc}
\hline & Length [M] & Width [M] & $\begin{array}{c}\text { Standard } \\
\text { Depth [M] }\end{array}$ & $\begin{array}{c}\text { Shallow Point } \\
{[\mathbf{M}]}\end{array}$ & $\begin{array}{c}\text { Average Tidal } \\
\text { Range [M] }\end{array}$ \\
\hline Outer channel & 32,000 & 230 & -12.6 & 10.1 & 3.9 \\
Inner channel & 6000 & 210 & -11.8 & 9.5 & \\
\hline \multicolumn{5}{c}{ Data source: [34]. }
\end{tabular}

\section{(2) Tidal Data.}

Figure 8 provides the tidal data of Yueqing Bay in June [35]. It is characterized as the semi-diurnal tide. The black and the adjacent grey bars indicate the high tide and the low tide in each day. The 5th and 23rd have the highest tide in a month, while the 15th has the lowest tide. The average high tide is about 537.1 [cm] (red line in Figure 8), and the average low tide is 95.57 [cm] (blue line in Figure 8). 


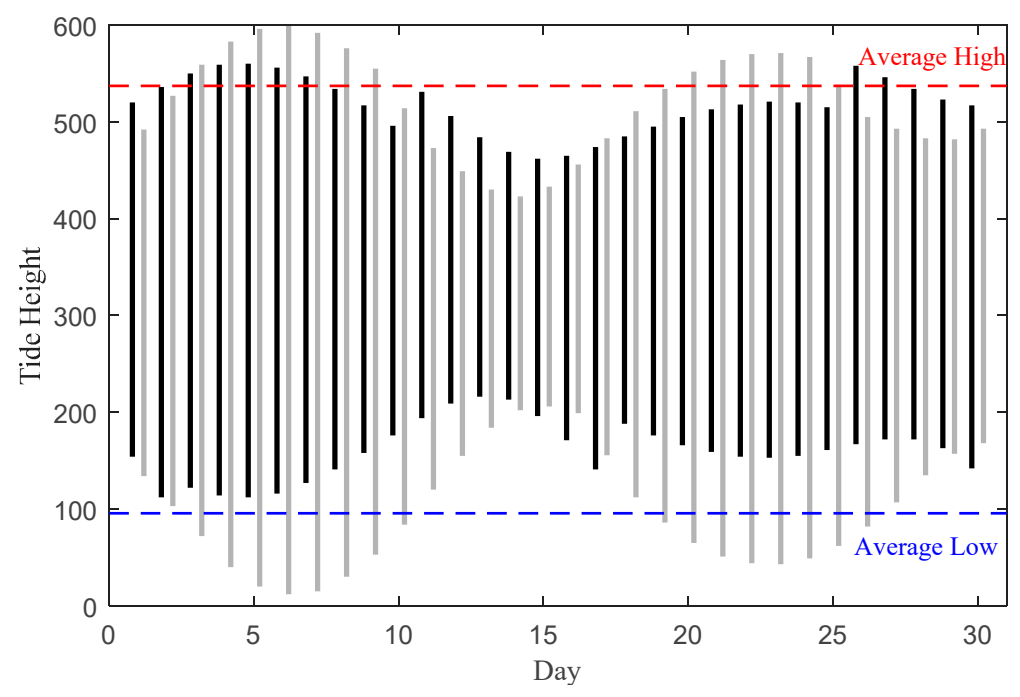

Figure 8. Tidal data of Yueqing Bay.

(3) Representative Ships.

By analyzing the historical traffic data (1.5 months), ships with a length of 50 100 [M] predominate in the total traffic flow. Therefore, ships with a length of $96 \mathrm{~m}$ are selected as the representation of OTS.

Considering the development of the international LNG transportation market and the infrastructure of the Damaiyu LNG terminal, a large LNG carrier $\left(165,000 \mathrm{~m}^{3}\right)$ is chosen as the objective ship type. Related parameters are shown in Table 3.

Table 3. Parameters of Representative ships. (OTS: Other Type of Ships; DWT: Deadweight Tonnage)

\begin{tabular}{ccccc}
\hline Ship Type & LOA [M] & $\begin{array}{c}\text { Molded Width } \\
{[\mathbf{M}]}\end{array}$ & $\begin{array}{c}\text { Molded Depth } \\
{[\mathbf{M}]}\end{array}$ & $\begin{array}{c}\text { Draft of } \\
\text { Bow/Stern [M] }\end{array}$ \\
\hline LNG carrier $\left(165,000 \mathrm{~m}^{3}\right)$ & 298.0 & 46.0 & 26.0 & 11.5 \\
OTS (3000 DWT) & 96.0 & 16.6 & 7.8 & 5.8 \\
\hline
\end{tabular}

Data source: [36].

Considering the rules of safe navigation and the limitation of the approach channel dimension, the average velocity of the LNG carrier is set to be $6[\mathrm{KN}]$. Meanwhile, the time of passing through the warning zone cannot be ignored. Then, the navigation time of the LNG carrier is about $4 \mathrm{~h}\left(T_{\mathrm{LNG}}\right)$ under this circumstance.

The length of the mobile safety zone for LNG carriers is set as 1.5 [NM] (1 [NM] bow distance and $0.5[\mathrm{NM}]$ stern distance). The transverse distance of the mobile safety zone is the width of the channel. The Yueqing Bay approach channel adopts the traffic separation scheme, so the largest width of the mobile safety zone is 400 [M], 200 [M] on both sides. According to the dimension of the LNG carrier and Equation (10), the tidal height that is necessary for safe navigation of LNG is 3.95 [M]. Therefore, the average duration of tidal height that satisfied the requirements of LNG carriers about $4.5 \mathrm{~h}$ per day.

The average velocity of OTS is set as 8 knots. Since the OTS are deemed to be the same performance. Moreover, based on traffic density and conditions of the channel, $d_{4}$ is set to be one and a half times of $l_{\text {lat }}$.

\subsection{Traffic Capacity of the Approach Channel}

The total spatial-temporal resources of the approach channel in one day $(24 \mathrm{~h})$ is obtained as follows:

$$
C_{t}=\int_{t_{1}}^{t_{2}} L_{C} \times B_{\mathcal{C}} \times N \times d_{t}=2068.8 \times 10^{5}\left[\mathrm{~m}^{2} \cdot \mathrm{h}\right]
$$


The stop spatial-temporal resources are given:

$$
C_{\text {sto }}=\int_{T_{0}}^{T_{1}} L_{C} \times B_{\mathcal{C}} \times N \times d_{t}=86.2 \times 10^{5}\left[\mathrm{~m}^{2} \cdot \mathrm{h}\right]
$$

The used spatial-temporal resources of LNG carrier can be figured out:

$$
C_{\mathrm{LNG}}=A_{\mathrm{LNG}} \times T_{\mathrm{LNG}}=44.448 \times 10^{5}\left[\mathrm{~m}^{2} \cdot \mathrm{h}\right]
$$

According to the size of the mobile safety zone, the time window for LNG carriers to pass through the approaching channel is when the tidal height is $13.60 \mathrm{~m}$. Based on the setting and the time of impact, the occupied spatial-temporal resources of the individual OTS in $5 \mathrm{~h}$ as follows:

$$
\begin{gathered}
h_{\text {ship }}=d_{2}+d_{4}+l_{\text {lat }}=281.156 \approx 282[\mathrm{~m}] . \\
C_{\text {ind }}=\int_{t_{3}}^{t_{4}} h_{\text {ship }} \times b \times d_{t}=14.1 \times 10^{5}\left[\mathrm{~m}^{2} \cdot \mathrm{h}\right] .
\end{gathered}
$$

Beyond that, the decreasing number of OTS $\left(N_{\text {los }}\right)$ because of the impacts of the LNG carrier is figured out. Thus, the influence of the LNG carrier on the approach channel is quantitatively analyzed. The loss of spatial-temporal resource contains $C_{\text {los }}$, the $C_{\mathrm{LNG}}$ and the unoccupied spatial-temporal resources $\left(C_{\text {uopd }}\right)$ in LNG carrier navigation time:

$$
\begin{gathered}
C_{\text {los }}=C_{\text {sto }}+C_{\text {uopd }}+C_{\mathrm{LNG}}=355.912 \times 10^{5}\left[\mathrm{~m}^{2} \cdot \mathrm{h}\right] \\
N_{\text {los }}=\frac{C_{\text {los }}}{C_{\text {ind }}}=252.419 \approx 252 \\
P_{\text {los }}=\frac{C_{\text {los }}}{C_{t}} \times 100 \% \approx 17.18 \%
\end{gathered}
$$

The spatial-temporal indexed chart for the research area is shown in Figure 9. If the channel resources are simplified as the sum of entire units, the yellow unit group spent $4 \mathrm{~h}$ to pass through this part of the channel. When LNG carriers are navigating in the channel based on the exclusive traffic pattern, ships from the opposite direction are not allowed to enter the channel. Only those ships in the same direction and their velocity are lower than the LNG carriers are allowed to follow the LNG carriers. Thus, the hidden units $(-1,2,2),(-1,2,3),(-1,3,3),(-1,4,3)$, are used by OTS.

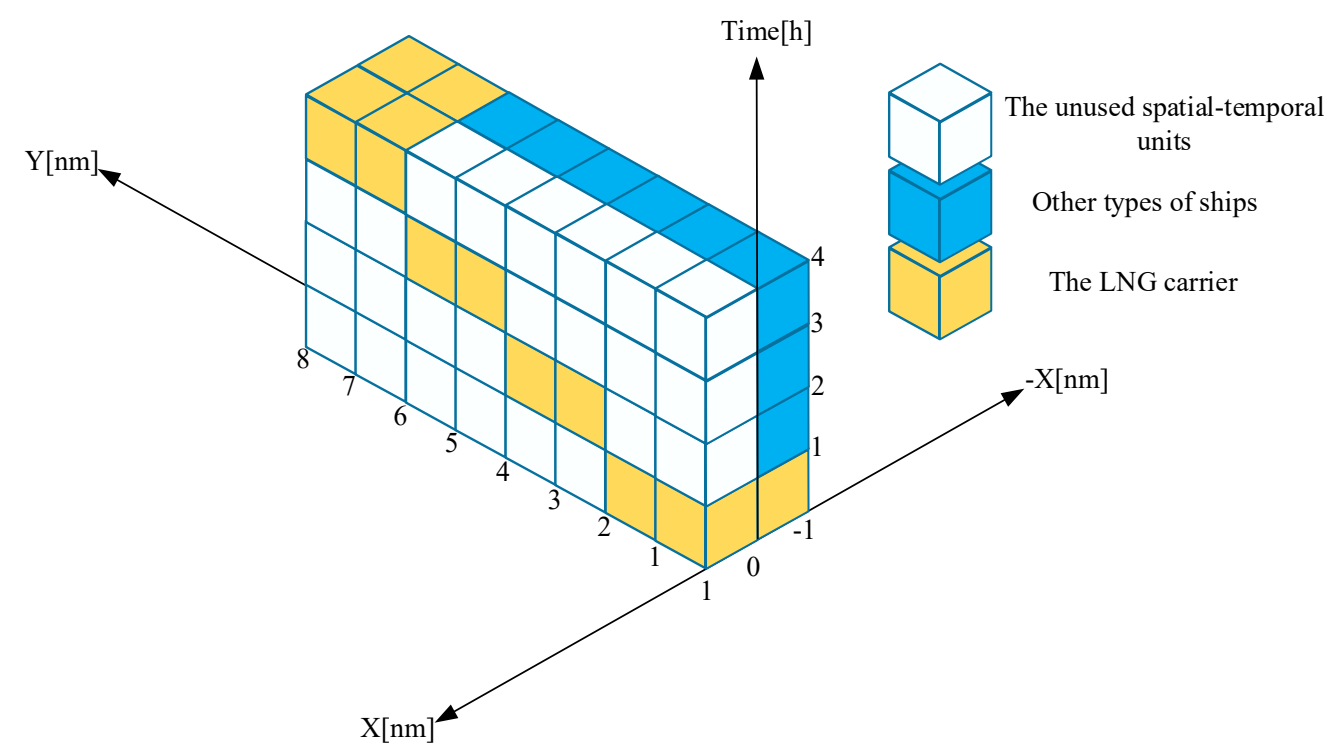

Figure 9. Spatial-temporal indexed chart of the approach channel in the research area. 
The white units represent the unused spatial-temporal resources when LNG carriers pass through this part of the channel. White units account for $75 \%$ at the remaining channel resources when LNG carriers are passing through. This kind of change of units occurs in every part of the whole channel. It can be found that the LNG carrier uses 16 units, and OTS use 12 units, the maximum number of ships that can pass through the channel each hour is at most 1 LNG carrier and 6 OTS.

\subsection{Sensitivity Analysis}

In this section, we analyze the impact of mobile safety zones, the arrival rate of LNG carriers, and velocity on traffic capacity. To indicate their effects, a new parameter, utilization rate, is introduced, which is defined as:

$$
P_{\text {use }}=\frac{C_{t}-C_{\text {los }}}{C_{t}} \times 100 \%
$$

\subsubsection{Impact of the Size of the Mobile Safety Zones}

The size of the mobile safety zones, especially the longitudinal length, determines the spatial-temporal resources that the LNG carriers occupied. Table 4 shows the utilization rate of the approach channel when the longitudinal length of the mobile safety zone changes from 1-3 [NM]. Obviously, the utilization rate decreases when the length of the safety zone increases.

Table 4. Changes of related parameters at different length of mobile safety zone.

\begin{tabular}{cccccc}
\hline $\begin{array}{c}\text { Length of the Mobile } \\
\text { Safety Zone [NM] }\end{array}$ & $\begin{array}{c}\boldsymbol{C}_{\mathbf{L N G}} \\
{\left[\mathbf{m}^{2} \cdot \mathbf{h}\right]}\end{array}$ & $\begin{array}{c}\boldsymbol{C}_{\mathbf{u o p d}} \\
{\left[\mathbf{m}^{2} \cdot \mathbf{h}\right]}\end{array}$ & $\begin{array}{c}\boldsymbol{C}_{\mathbf{l o s}} \\
{\left[\mathbf{m}^{2} \cdot \mathbf{h}\right]}\end{array}$ & $\begin{array}{c}\boldsymbol{P}_{\text {los }} \\
{[\%]}\end{array}$ & $\begin{array}{c}\boldsymbol{P}_{\text {use }} \\
{[\%]}\end{array}$ \\
\hline 1 & $2,960,000$ & $23,640,000$ & $35,220,800$ & $17.02 \%$ & $82.98 \%$ \\
1.5 & $4,444,800$ & $22,526,400$ & $35,591,200$ & $17.20 \%$ & $82.80 \%$ \\
2 & $5,926,400$ & $21,415,200$ & $35,961,600$ & $17.38 \%$ & $82.62 \%$ \\
2.5 & $7,408,000$ & $20,304,000$ & $36,332,000$ & $17.56 \%$ & $82.44 \%$ \\
3 & $8,889,600$ & $19,192,800$ & $36,702,400$ & $17.74 \%$ & $82.26 \%$ \\
\hline
\end{tabular}

\subsubsection{Impact of Arrival Rate}

The number of LNG carriers has significant impacts on the capacity and the utilization rate. Here, we calculate the utilization rate when the LNG carriers arrive during the time window change from 1 to 3 , see Table 5. When more LNG carriers arrive at the port, more spatial-temporal resources are occupied by LNG carriers, and less OTS can enter the approach channel. Therefore, the utilization rate becomes lower. The maximum number of LNG carriers that the approach channel can contain is 3, given the daytime equals 12 [h], and the time of LNG carrier finishing the approach channel is $4 \mathrm{~h}$ without overlapping each other.

Table 5. Related parameters at a different arrival rate.

\begin{tabular}{cccccc}
\hline $\begin{array}{c}\text { Arrival Rate } \\
\text { [Ships/Day] }\end{array}$ & $\begin{array}{c}C_{\mathbf{L N G}} \\
{\left[\mathbf{m}^{2} \cdot \mathbf{h}\right]}\end{array}$ & $\begin{array}{c}\boldsymbol{C}_{\mathbf{u o p d}} \\
{\left[\mathbf{m}^{2} \cdot \mathbf{h}\right]}\end{array}$ & $\begin{array}{c}\boldsymbol{C}_{\mathbf{l o s}} \\
{\left[\mathbf{m}^{2} \cdot \mathbf{h}\right]}\end{array}$ & $\begin{array}{c}\boldsymbol{P}_{\text {los }} \\
{[\%]}\end{array}$ & $\begin{array}{c}\boldsymbol{P}_{\mathbf{u s e}} \\
{[\%]}\end{array}$ \\
\hline 1 & $4,444,800$ & $22,526,400$ & $35,591,200$ & $17.20 \%$ & $82.80 \%$ \\
2 & $8,889,600$ & $45,052,800$ & $62,562,400$ & $30.24 \%$ & $69.76 \%$ \\
3 & $13,334,400$ & $67,579,200$ & $89,533,600$ & $43.28 \%$ & $56.72 \%$ \\
\hline
\end{tabular}

\subsubsection{Impact of Velocity}

The velocities of the LNG carriers determine their navigation time, which, therefore, has a high impact on the capacity and utilization rate of the channel. In this section, we investigate the effects of velocity. The maximum permissible speed of LNG carriers at Yueqing Bay is 12 [KN], the minimum velocity to ensure the maneuverability is 6 [KN]. As shown in Figure 7, the approach channel of 
Yueqing Bay has two turning points, i.e., Point ${ }_{1}$ and Point 2 . The distance between the entrance, Point ${ }_{1}$, Point $_{2}$, and the destination is $24[\mathrm{~km}], 8[\mathrm{~km}], 6[\mathrm{~km}]$, respectively.

(1) Constant Velocity

In this part, the velocity of the LNG carriers throughout the whole voyage remains constant. We compared the traffic capacity under the different velocities of LNG carrier, from 6 [KN] to $12[\mathrm{KN}]$, see Table 6 . The change of velocity means the shift in navigation time as well as the used spatial-temporal resources $\left(C_{\mathrm{LNG}}\right)$, see Figure 10 . The utilization rate of the channel is $82-89 \%$ when the velocities of LNG carriers navigating inside increase from $6[\mathrm{KN}]$ to $12[\mathrm{KN}]$. Higher velocity indicates shorter navigation time and, therefore, a higher utilization rate. However, the increasing rate slightly decreases when the velocity increases.

Table 6. Changes of related parameters at different velocity.

\begin{tabular}{ccccccc}
\hline $\begin{array}{c}\text { Velocity } \\
{[\text { KN] }}\end{array}$ & $\begin{array}{c}\text { Navigation } \\
\text { Time }[\mathbf{h}]\end{array}$ & $\begin{array}{c}\boldsymbol{C}_{\mathbf{L N G}} \\
{\left[\mathbf{m}^{2} \cdot \mathbf{h}\right]}\end{array}$ & $\begin{array}{c}\boldsymbol{C}_{\text {uopd }} \\
{\left[\mathbf{m}^{2} \cdot \mathbf{h}\right]}\end{array}$ & $\begin{array}{c}\boldsymbol{C}_{\text {los }} \\
{\left[\mathbf{m}^{2} \cdot \mathbf{h}\right]}\end{array}$ & $\begin{array}{c}\boldsymbol{P}_{\text {los }} \\
{[\%]}\end{array}$ & $\begin{array}{c}\boldsymbol{P}_{\text {use }} \\
{[\%]}\end{array}$ \\
\hline 6 & 4.0 & $4,444,800$ & $22,526,400$ & $35,591,200$ & $17.20 \%$ & $82.80 \%$ \\
7 & 3.5 & $3,889,200$ & $19,710,600$ & $32,219,800$ & $15.57 \%$ & $84.43 \%$ \\
8 & 3.2 & $3,555,840$ & $18,021,120$ & $30,196,960$ & $14.60 \%$ & $85.40 \%$ \\
9 & 2.9 & $3,222,480$ & $16,331,640$ & $28,174,120$ & $13.62 \%$ & $86.38 \%$ \\
10 & 2.7 & $3,000,240$ & $15,205,320$ & $26,825,560$ & $12.97 \%$ & $87.03 \%$ \\
11 & 2.5 & $2,778,000$ & $14,079,000$ & $25,477,000$ & $12.32 \%$ & $87.69 \%$ \\
12 & 2.3 & $2,555,760$ & $12,952,680$ & $24,128,440$ & $11.66 \%$ & $88.34 \%$ \\
\hline
\end{tabular}

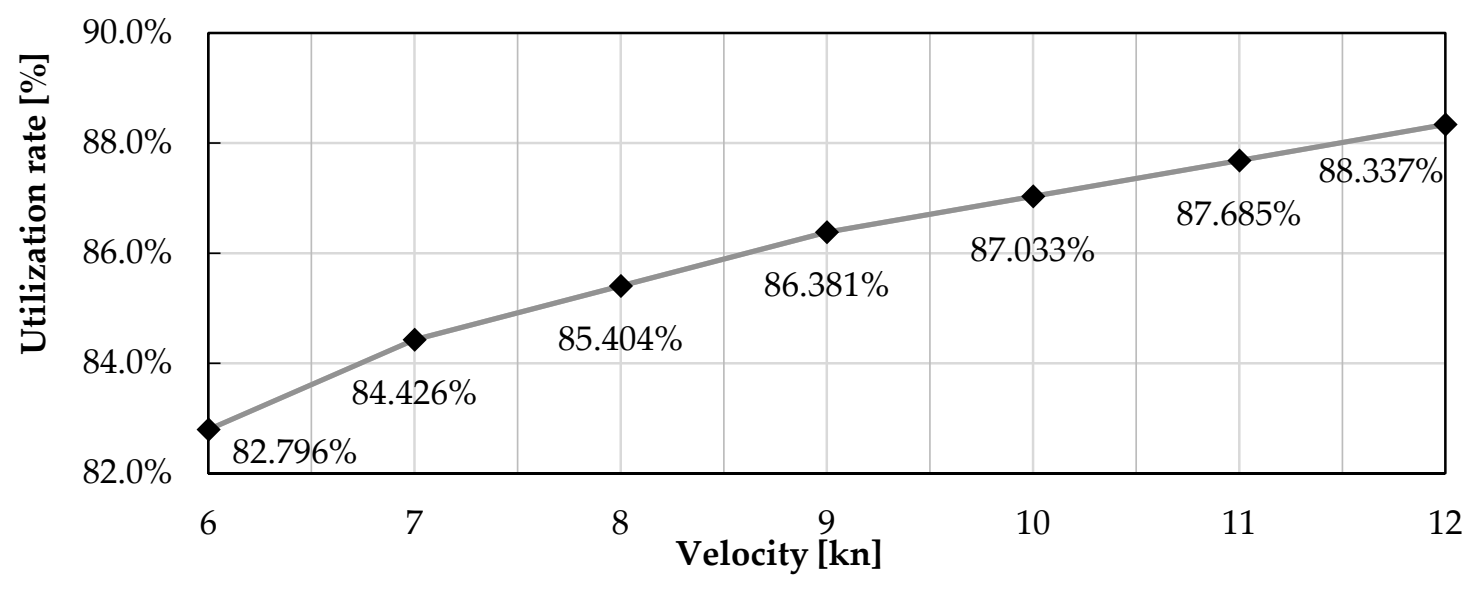

Figure 10. Utilization rate with different velocities.

\section{(2) Changing Velocity}

Considering the routine operation of navigation, the velocity is a variable when the LNG carriers are entering the port. In this part, we set two different velocity changing patterns, i.e., continuous decrease and varying velocity; see Table 7 . In the pattern of constant decline, we assume that the LNG carriers use the maximum permissible velocity to finish the two-thirds (before the first turning point) and decrease at each turning point. In the pattern of varying velocity, LNG carriers frequently accelerate and decelerate: LNG carriers firstly accelerate until the maximum permissible velocity and then decelerate when close to the turning points. Usually, the LNG carriers need to spend about $5 \mathrm{~min}$ to change the speed. 
Table 7. Velocity in different Scenes [KN].

\begin{tabular}{|c|c|c|c|c|c|}
\hline Pattern & $\begin{array}{l}\text { Scene } \\
\text { NO. }\end{array}$ & $\begin{array}{c}\text { Entrance- } \\
\text { Point }_{1}\end{array}$ & $\begin{array}{c}\text { Point }_{1}- \\
\text { Point }_{2}\end{array}$ & $\begin{array}{c}\text { Point }_{2}- \\
\text { Destination }\end{array}$ & $\begin{array}{c}\text { Navigation } \\
\text { Time [h] }\end{array}$ \\
\hline \multirow{16}{*}{$\begin{array}{l}\text { Continuous } \\
\text { deceleration }\end{array}$} & 1 & \multirow{16}{*}{12} & \multirow{5}{*}{11} & 10 & 2.40 \\
\hline & 2 & & & 9 & 2.43 \\
\hline & 3 & & & 8 & 2.48 \\
\hline & 4 & & & 7 & 2.54 \\
\hline & 5 & & & 6 & 2.61 \\
\hline & 6 & & \multirow{4}{*}{10} & 9 & 2.47 \\
\hline & 7 & & & 8 & 2.52 \\
\hline & 8 & & & 7 & 2.55 \\
\hline & 9 & & & 6 & 2.65 \\
\hline & 10 & & \multirow{3}{*}{9} & 8 & 2.56 \\
\hline & 11 & & & 7 & 2.62 \\
\hline & 12 & & & 6 & 2.70 \\
\hline & 13 & & \multirow{2}{*}{8} & 7 & 2.68 \\
\hline & 14 & & & 6 & 2.76 \\
\hline & 15 & & 7 & 6 & 2.83 \\
\hline & 16 & & 6 & 6 & 2.94 \\
\hline Varying velocity & 17 & $9-12$ & $9-12-9$ & $9-12-9$ & 2.39 \\
\hline
\end{tabular}

Table 8 provides the utilization rates of different scenes. We can find that Scene NO.17 in which LNG carriers varying their velocities during navigation has the highest utilization rate.

Table 8. Related parameters in different scenes.

\begin{tabular}{|c|c|c|c|c|c|c|c|}
\hline Pattern & $\begin{array}{c}\text { Scene } \\
\text { NO. }\end{array}$ & $\begin{array}{c}\text { Navigation } \\
\text { Time [h] }\end{array}$ & $\begin{array}{l}C_{\mathrm{LNG}} \\
{\left[\mathrm{m}^{2} \cdot \mathrm{h}\right]}\end{array}$ & $\begin{array}{l}C_{\text {uopd }} \\
{\left[\mathbf{m}^{2} \cdot \mathbf{h}\right]}\end{array}$ & $\begin{array}{c}C_{\text {los }} \\
{\left[\mathbf{m}^{2} \cdot \mathbf{h}\right]}\end{array}$ & $\begin{array}{l}P_{\text {los }} \\
{[\%]}\end{array}$ & $\begin{array}{c}P_{\text {use }} \\
{[\%]}\end{array}$ \\
\hline \multirow{16}{*}{$\begin{array}{l}\text { Continuous } \\
\text { deceleration }\end{array}$} & 1 & 2.40 & $2,666,880$ & $13,515,840$ & $24,802,720$ & $11.99 \%$ & $88.01 \%$ \\
\hline & 2 & 2.43 & $2,700,216$ & $13,684,788$ & $25,005,004$ & $12.09 \%$ & $87.91 \%$ \\
\hline & 3 & 2.48 & $2,755,776$ & $13,966,368$ & $25,342,144$ & $12.25 \%$ & $87.75 \%$ \\
\hline & 4 & 2.54 & $2,822,448$ & $14,304,264$ & $25,746,712$ & $12.45 \%$ & $87.55 \%$ \\
\hline & 5 & 2.61 & $2,900,232$ & $14,698,476$ & $26,218,708$ & $12.67 \%$ & $87.33 \%$ \\
\hline & 6 & 2.47 & $2,744,664$ & $13,910,052$ & $25,274,716$ & $12.22 \%$ & $87.78 \%$ \\
\hline & 7 & 2.52 & $2,800,224$ & $14,191,632$ & $25,611,856$ & $12.38 \%$ & $87.62 \%$ \\
\hline & 8 & 2.55 & $2,833,560$ & $14,360,580$ & $25,814,140$ & $12.48 \%$ & $87.52 \%$ \\
\hline & 9 & 2.65 & $2,944,680$ & $14,923,740$ & $26,488,420$ & $12.80 \%$ & $87.20 \%$ \\
\hline & 10 & 2.56 & $2,844,672$ & $14,416,896$ & $25,881,568$ & $12.51 \%$ & $87.49 \%$ \\
\hline & 11 & 2.62 & $2,911,344$ & $14,754,792$ & $26,286,136$ & $12.71 \%$ & $87.29 \%$ \\
\hline & 12 & 2.70 & $3,000,240$ & $15,205,320$ & $26,825,560$ & $12.97 \%$ & $87.03 \%$ \\
\hline & 13 & 2.68 & $2,978,016$ & $15,092,688$ & $26,690,704$ & $12.90 \%$ & $87.10 \%$ \\
\hline & 14 & 2.76 & $3,066,912$ & $15,543,216$ & $27,230,128$ & $13.16 \%$ & $86.84 \%$ \\
\hline & 15 & 2.83 & $3,144,696$ & $15,937,428$ & $27,702,124$ & $13.39 \%$ & $86.61 \%$ \\
\hline & 16 & 2.94 & $3,266,928$ & $16,556,904$ & $28,443,832$ & $13.75 \%$ & $86.25 \%$ \\
\hline Varying velocity & 17 & 2.39 & $2,655,768$ & $13,459,524$ & $24,735,292$ & $11.96 \%$ & $88.04 \%$ \\
\hline
\end{tabular}




\subsubsection{Comparison of Different Traffic Management Strategies}

In this part, we combine the set of the mobile safety zone and the velocity changing scenes and make specific traffic management strategies. The 17 scenes mentioned above are combined with different lengths of mobile safety zones. The utilization rates are shown in Figure 11.

According to the results, Scene 17 has higher utilization rates than other scenes, even when the mobile safety zone is large. Other scenes are grouped according to their velocity at the segment Point $_{1}$ - Point ${ }_{2}$, and the utilization rate decrease with their velocities at the segment Point ${ }_{2}$-Destination. From the comparison, we can find that longer navigation time results in lower utilization rate.

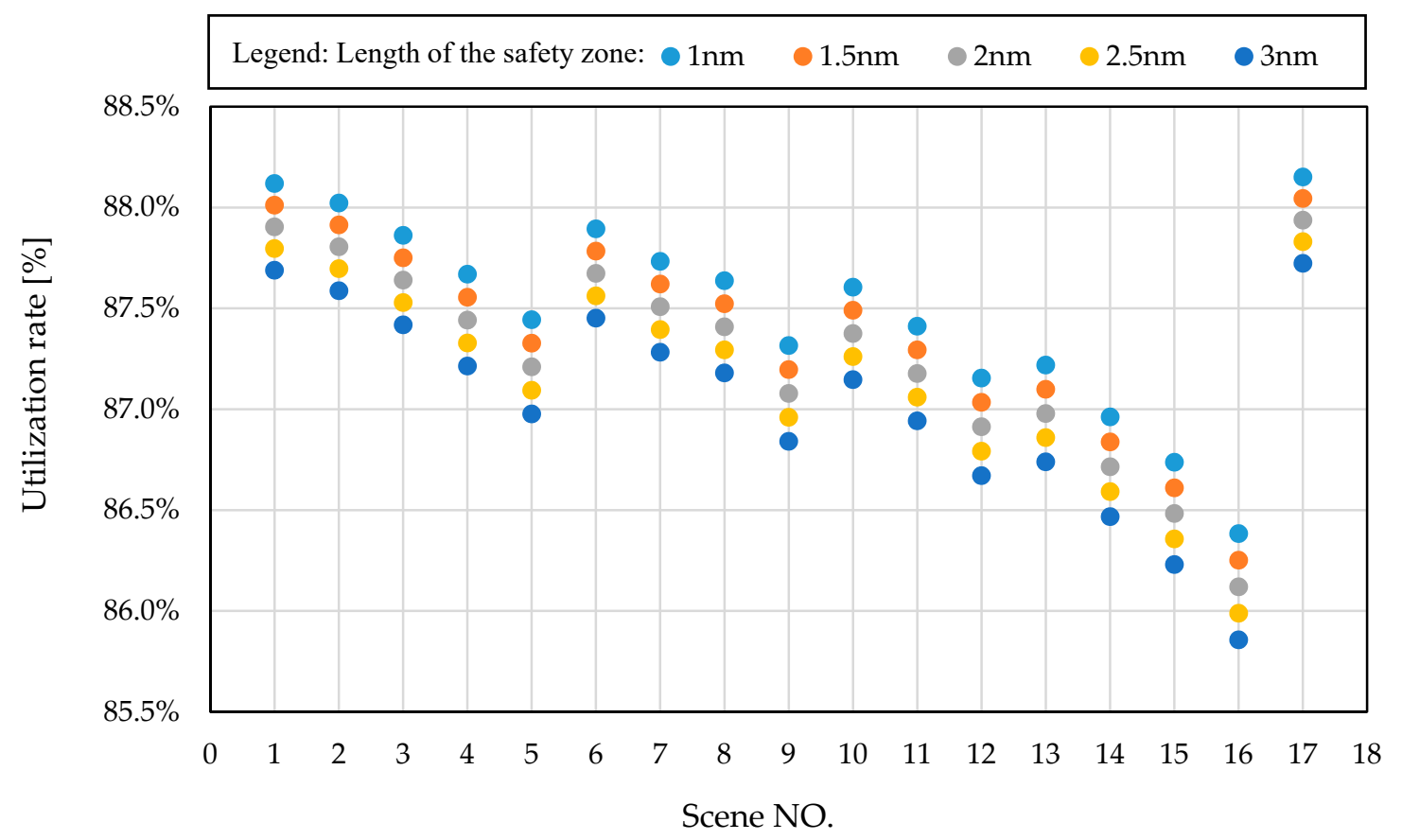

Figure 11. Comparison of utilization rates using different traffic management strategies.

\subsection{Discussion}

Through the above experiments, the navigation of the LNG carrier has an enormous effect on the traffic flow. According to the characteristics of LNG carriers, LNG carriers need larger mobile safety zones and only can enter the approach channel during the time windows calculated according to the tide. Therefore, when an approach channel is shared by LNG carriers and OTS, the traffic capacity of the channel is reduced, as well as the utilization rate. The reduction in capacity and utilization rate is determined by the size of mobile safety zones, arrival rate, and the velocity of the LNG carriers that arrive at the port. The change of mobile safety zone and the variation of velocity have the same effects on $N_{\text {los }}$. Extending the length of the mobile safety zone results in a decrease in the number of OTS. Two ships decrease in $N_{\text {los }}$ while the mobile safety zone changes every 0.5 [NM]. Meanwhile, one ship decreases in $N_{\text {los }}$ when the velocity reduces every 1 [KN]. The proportion of loss number of OTS in the total amount is $11.8-14.1 \%$.

According to the experiments, we get the following conclusions. Firstly, the utilization rate increases with the velocity of the LNG carrier. $P_{\text {use }}$ can be improved by adjusting speed, but this kind of improvement has its limits and $P_{\text {use }}$ has an upper bound. Secondly, the mobile safety zone is directly proportional to $P_{\text {use }}$ when the velocity is fixed. Therefore, if the weather and oceanic conditions are good, the authorities can suggest smaller mobile safety zones and higher velocities to increase the traffic capacity. 


\section{Conclusions}

In this paper, we propose a framework for capacity analysis of shared approach channels based on spatial-temporal consumption. The framework consists of three modules: (1) the generic spatial-temporal consumption module is introduced to calculate the capacity of approach channels; (2) the LNG carrier navigation module is for analyzing the characteristics of LNG carriers and the impact on the capacity of approach channels; (3) the tide module predicts the tidal height and tidal time for identifying the time windows that LNG carriers can sail. A spatial-temporal indexed chart is designed to visualize the utilization of the spatial-temporal resources. A case study on the Yueqing Bay approach channel on the east coast of China is chosen as a case study to demonstrate the effectiveness of the framework. The utilization rates of the approach channel and the impact of mobile safety zones, arrival rate, and velocity of LNG carriers are presented.

According to the results of sensitivity analysis, traffic management strategies to improve the capacity of a shared approach channel are made:

1. If the arrival rate of the LNG carrier reaches a critical value, which is the maximum number of LNG carriers, OTS cannot use the channel during the tide window. Then the authority could plan to build a special channel to separate the LNG carriers and OTS.

2. The utilization rates of the shared channel are affected more by the mobile safety zone than the change of the velocity. Thus, the authorities can improve the utilization rate of the channel by control the size of the mobile safety zone and design an optimal velocity changing pattern.

3. However, smaller safety zone and higher speed of LNG carriers may increase the navigation risk. Therefore, balancing efficiency and safety is a significant factor that needs to be considered when making traffic management strategies.

In future works, some parameters adopted in this paper should quantitatively assessed other than relying on the statistics or experiences, although the empirical figure is relatively accurate and straightforward to get. As for OTS, more kinds of ship types will be adopted in the module based on their proportion in the traffic flow. Moreover, other methods, such as simulation, will be applied for comparison. Moreover, it will be more accordant with the real traffic conditions if there are two or more traffic flows in the channel. Furthermore, traffic scheduling methods will be applied to further improve the utilization rate of the channels, as well as the trade-off between the priorities of OTS and LNG carriers [37]. Last but not the least, as mentioned, balancing efficiency and risk is significant when making strategies. Thus, risk analysis of LNG carriers and OTS is needed in the next step [38].

Author Contributions: Conceptualization, L.C. and J.M.; methodology, L.C. and P.C.; formal analysis, X.G. and Y.L.; investigation, X.G. and L.C.; data curation, X.G. and Y.L.; writing-original draft preparation, X.G.; writing-review and editing, L.C. and P.C.; visualization, X.G.; supervision, L.C. and J.M.; project administration, L.C. and J.M.; funding acquisition, J.M. All authors have read and agreed to the published version of the manuscript.

Funding: This research was funded by the National Innovation and Entrepreneurship Training Program for College Students grant number S202010497234 and the Independent Innovation Foundation of Wuhan University of Technology grant number 2020-zy-196.

Conflicts of Interest: The authors declare no conflict of interest. 


\section{Appendix A}

Table A1. List of variables.

\begin{tabular}{|c|c|c|c|}
\hline Symbol & Variables & Symbol & Variables \\
\hline UKC & Under keel Clearance & $t_{3}, t_{4}$ & The period that a ship navigates in the channel \\
\hline $\mathrm{D}$ & Draft & $h_{\text {ship }}$ & Safety distance between the consecutive ships \\
\hline$\left(h_{\text {tide }}\right)$ & Height of the tide & $b$ & The track zone width of the individual ship. \\
\hline$\left(d_{\text {chart }}\right)$ & the charted depth & $T$ & Workable time of the channel in a single day \\
\hline$(T D)$ & Tidal datum & $t_{\text {ship }}$ & Average time that a ship used in $T$ \\
\hline$(C D)$ & Chart datum & $d_{2}$ & Crash-stop distance of the later ship \\
\hline (s) & Ship squat & $d_{1}$ & Distance in reacting time \\
\hline$(\varepsilon)$ & Water level measuring error & $d_{4}$ & Static safety distance \\
\hline$(\omega)$ & Ship swaying increment & $d_{3}$ & Crash-stop distance of the former ship \\
\hline$\left(h_{\mathrm{R}}\right)$ & Relative depth & $l_{\text {lat }}$ & Length of the former ship \\
\hline$h_{\text {real }}$ & Real depth & $v_{\text {lat }}$ & Velocity of the later ship \\
\hline$L p p$ & Length between perpendiculars & $t_{\text {rea }}$ & Reaction time \\
\hline $\mathrm{Cb}$ & Block coefficients of ship & $A_{\text {in }}$ & Plane area of the inbound ship domain \\
\hline$d_{\text {channel }}$ & The depth of the channel & $t_{\text {in }}$ & Inbound time \\
\hline$B$ & Molded breadth & $l_{\text {ad }}$ & Length of the inbound ship \\
\hline V & Ship displacement & $v_{\mathrm{ad}}$ & Velocity of the inbound ship \\
\hline$F r$ & Froude number of ship length & $d_{\mathrm{ad}}$ & Inbound distance \\
\hline$F n$ & Froude number of channel depth & $v_{\text {ave }}$ & Average velocity of the ships navigated in the channel \\
\hline$v_{l}$ & Ship velocity & $d_{\text {safe }}$ & Safety distance \\
\hline$g$ & Gravity & $L_{\text {zone }}$ & Length of longitudinal direction \\
\hline$\left(\mathrm{h}_{N}\right)$ & Tidal height & $B_{\text {zone }}$ & Width in the transverse direction \\
\hline$h_{\text {high }}, t_{\text {high }}$ & The height and duration of high water & $A_{\mathrm{LNG}}$ & Navigation plane area of the safety zone \\
\hline $\mathrm{h}_{\text {low }}, t_{\text {low }}$ & The height and duration of low water & $T_{\text {LNG }}$ & Navigation time of LNG carriers \\
\hline$R$ & Tidal range & $C_{\mathrm{LNG}}$ & Spatial-temporal resources of LNG \\
\hline $\mathrm{C}$ & Traffic capacity & $C_{\text {sto }}$ & Suspension of the spatial-temporal resources \\
\hline$C_{t}$ & Total spatial-temporal resources & $C_{\text {ord }}$ & Used spatial-temporal resources by other types of ships \\
\hline$t_{1}, t_{2}$ & Time period & $C_{t l n g}$ & Occupied spatial-temporal resources by LNG carriers \\
\hline$L_{C}$ & Overall length of the channel & $C_{\text {uopd }}$ & $\begin{array}{c}\text { Unused spatial-temporal resources in the time of LNG } \\
\text { carrier's navigation }\end{array}$ \\
\hline$B_{C}$ & The maximum available width of channel & $C_{\text {los }}$ & Loss of spatial-temporal resources \\
\hline$N$ & The number of the passageway in the channel & $P_{\text {los }}$ & Loss rate of spatial-temporal resources \\
\hline$C_{\text {ind }}$ & Resource that the individual ship occupied & $N_{\text {los }}$ & Loss number of other types of ships \\
\hline
\end{tabular}

\section{References}

1. Wang, W.; Peng, Y.; Tian, Q.; Song, X. Key influencing factors on improving the waterway through capacity of coastal ports. Ocean Eng. 2017, 137, 382-393. [CrossRef]

2. International Energy Agency. World Energy Outlook 2019; Organisation for Economic Co-Operation and Development (OECD): Paris, France, 2019.

3. Liu, K.; Xin, X.; Ma, J.; Zhang, J.; Yu, Q. Sensitivity analysis of ship traffic in restricted two-way waterways considering the impact of LNG carriers. Ocean Eng. 2019, 192, 106556. [CrossRef]

4. Olba, X.B.; Daamen, W.; Vellinga, T.; Hoogendoorn, S.P. Capacity Estimation Method of a Waterway Intersection. In Traffic and Granular Flow '15; Springer Science and Business Media LLC: Berlin/Heidelberg, Germany, 2016; Volume 1920, pp. 613-620.

5. Wei, Z. Calculation model of inland waterway transit capacity based on ship-following theory. J. Traffic Transp. Eng. 2009, 9, 83-87.

6. Zhang, X.; Mou, J.; Zhu, J.; Chen, P.; Liu, R. (Rachel) Capacity Analysis for Bifurcated Estuaries Based on Ship Domain Theory and its Applications. Transp. Res. Rec. J. Transp. Res. Board 2017, 2611, 56-64. [CrossRef] 
7. Chen, L.; Mou, J.; Dai, J.; Wen, Y. Traffic Capacity of Inland Waterway Network Base on Space-time Occupation Analysis. J. Navig. China 2013, 36, 76-81.

8. de Oliveira Mota, D.; Botter, R.C. Ship traffic capacity model for the largest port in Latin America. Mar. Syst. Ocean Technol. 2019, 15, 45-56. [CrossRef]

9. Shang, J.; Wang, W.; Peng, Y.; Tian, Q.; Tang, Y.; Guo, Z. Simulation research on the influence of special ships on waterway through capacity for a complex waterway system: A case study for the Port of Meizhou Bay. Simulation 2019, 96, 387-402. [CrossRef]

10. Zhang, J.; Yuan, L.; Wang, R. Y(4220)Y(4220) and Y(4390)Y(4390). Evaluating Waterway Transit Capacity Based on AHP-Fuzzy Comprehensive Method. In Proceedings of the International Conference on Transportation (ICTR 2013), Xianning, China, 4-6 December 2013.

11. Wang, W.; Peng, Y.; Song, X.; Zhou, Y. Impact of Navigational Safety Level on Seaport Fairway Capacity. J. Navig. 2015, 68, 1120-1132. [CrossRef]

12. PIANC. PIANC Report: Design of Small-to Mid-Scale Marine LNG Terminals Including Bunkering; PIANC: Brussels, Belgium, 2016.

13. PIANC. PIANC Report: Safety Aspects Affecting the Berthing Operations of Tankers to Oil and Gas Terminals; PIANC: Brussels, Belgium, 2012.

14. Vanem, E.; Antao, P.; Østvik, I.; de Comas, F.D.C. Analyzing the risk of LNG carrier operations. Reliab. Eng. Syst. Saf. 2008, 93, 1328-1344. [CrossRef]

15. Abdussamie, N.; Daboos, M.; Elferjani, I.; Shuhong, C.; Alaktiwi, A.; Chai, S. Risk assessment of LNG and FLNG vessels during manoeuvring in open sea. J. Ocean Eng. Sci. 2018, 3, 56-66. [CrossRef]

16. Zhang, W. Historical accidents study for LNG carriers. Sh. Boat. 2011, 22, 7-11.

17. Nwaoha, T.C.; Yang, Z.; Wang, J.; Bonsall, S. Adoption of new advanced computational techniques to hazards ranking in LNG carrier operations. Ocean Eng. 2013, 72, 31-44. [CrossRef]

18. Ovidi, F.; Landucci, G.; Picconi, L.; Chiavistelli, T. A Risk-Based Approach for the Analysis of LNG Carriers Port Operations. In Proceedings of the 28th Annual International European Safety and Reliability Conference (ESREL), Trondheim, Norway, 17-21 June 2018.

19. Frederic, J. Shipping LNG from an Arctic LNG Plant: Some Marine Challenges. In Proceedings of the PIANC-World Congress, Panama City, Panama, 7-12 May 2018.

20. Jiao, Z.L.; Jiang, C.X. Properties and Safety Management about LNG Carrier. Appl. Mech. Mater. 2011, 99, 934-938. [CrossRef]

21. Maimun, A.; Priyanto, A.; Rahimuddin, R.; Sian, A.; Awal, Z.; Celement, C.; Nurcholis; Waqiyuddin, M. A mathematical model on manoeuvrability of a LNG tanker in vicinity of bank in restricted water. Saf. Sci. 2013, 53, 34-44. [CrossRef]

22. Elsayed, T. Fuzzy inference system for the risk assessment of liquefied natural gas carriers during loading/offloading at terminals. Appl. Ocean Res. 2009, 31, 179-185. [CrossRef]

23. Chen, L.-J.; Yan, X.; Huang, L.-W.; Yang, Z.; Wang, J. A systematic simulation methodology for LNG ship operations in port waters: A case study in Meizhou Bay. J. Mar. Eng. Technol. 2017, 17, 1-21. [CrossRef]

24. Wen, Y.; Yang, X.; Xiao, C. A Quantitative method for establishing the width of moving safety zone around LNG carrier. China Saf. Sci. J. 2013, 23, 68.

25. El-Diasty, M.; Al-Harbi, S.; Pagiatakis, S. Hybrid harmonic analysis and wavelet network model for sea water level prediction. Appl. Ocean Res. 2018, 70, 14-21. [CrossRef]

26. Chen, L. Study on Traffic Capacity of Waterway Network. Master's Thesis, Wuhan University of Technology, Wuhan, China, 2014.

27. Chen, C.; Ren, F.; Rong, J. Review of Road Network Capacity. J. Highw. Transp. Res. Dev. 2002, 3, 97-101.

28. Duan, L.; Wen, Y.; Dai, J.; Tang, M.; Mou, J. Calculation Model of Water-network Channel Transit Capacity Based on Theory of Space-time Consumption. Sh. Ocean Eng. 2012, 41, 134-137.

29. Zhang, H. The Study of Safety Zone When LNG Ship Entering and Leaving Port. Master's Thesis, Dalian Maritime University, Dalian, China, 2015.

30. Ministry of Transport of the People's Republic of China. Code for Design of Liquefied Natural Gas Port and Jetty. JTS 2016, 165, 5 .

31. Coast Guard, DHS, 33 CFR Ch. I(7-1-09 Edition)Part 165-Regulated Navigation Areas and Limited Access Areas. Available online: https://www.law.cornell.edu/cfr/text/33/part-165 (accessed on 8 September 2020).

32. Tuck, E.O. Sinkage and trim in shallow water of finite width. Schiffetechnik 1973, 14, 92-94. 
33. Hooft, J. The behaviour of a ship in head waves at restricted water depths1. Int. Shipbuild. Prog. 1974, 21, 367-390. [CrossRef]

34. Nautical Chart:13715, People's Liberation Army Navy, 2015.8. Available online: http://enc.ngd.gov.cn/ chartserach.aspx (accessed on 8 September 2020).

35. National Marine Data Center. National Science \& Technology Resource Sharing Service Platform of China. Available online: https://www.cnss.com.cn/tide/ (accessed on 8 September 2020).

36. Ministry of Transport of the People's Republic of China. Design Code of General Layout for Sea Ports. JTS165-2013. Available online: http://wtis.mot.gov.cn/syportalapply/sysnoticezl/sy/1?pageSize= $10 \&$ noticeType $=1 \&$ pageIndex $=0$ (accessed on 8 September 2020).

37. Zhang, J.; Santos, T.A.; Soares, C.G.; Yan, X. Sequential ship traffic scheduling model for restricted two-way waterway transportation. Proc. Inst. Mech. Eng. Part M J. Eng. Marit. Environ. 2016, 231, 86-97. [CrossRef]

38. Chen, P.; Huang, Y.; Mou, J.; Van Gelder, P. Probabilistic risk analysis for ship-ship collision: State-of-the-art. Saf. Sci. 2019, 117, 108-122. [CrossRef]

(C) 2020 by the authors. Licensee MDPI, Basel, Switzerland. This article is an open access article distributed under the terms and conditions of the Creative Commons Attribution (CC BY) license (http://creativecommons.org/licenses/by/4.0/). 